\title{
Small and Medium Enterprises (SMEs) in the Cloud in Developing Countries: A Synthesis of the Literature and Future Research Directions
}

\author{
Ibrahim Osman Adam ${ }^{1,2}$ \& Alhassan Musah ${ }^{1}$ \\ ${ }^{1}$ School of Business and Law, University for Development Studies, Wa, Ghana \\ ${ }^{2}$ University of Ghana Business School, Legon, Accra, Ghana \\ Correspondence: Ibrahim Osman Adam, School of Business and Law, University for Development Studies, Wa, \\ Ghana. E-mail: ioadam@uds.edu.gh
}

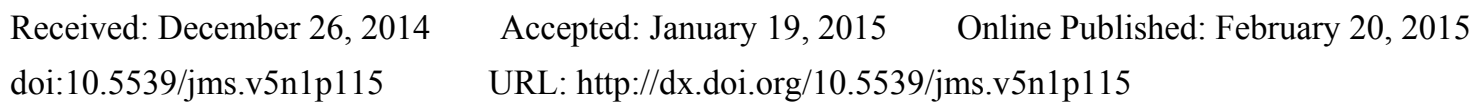

\begin{abstract}
Research in cloud computing is undergoing rapid growth since its evolution less than a decade ago. This paper contributes to the understanding of this growing research area and by this, considers the potential for cloud computing in small and medium enterprises (SMEs) in developing countries (DCs). The current state of research is assessed in a review of 95 research articles drawn from journals which are both peer-reviewed and academic. To do this, a framework is developed to categorise and analyse the research according to a socio-technical spectrum, identifying levels of analysis and differentiating research activity according to a lifecycle model that incorporates the requirement, needs and desires, adoption, use and adaptation and impact of SMEs in the cloud.
\end{abstract}

The highlights of research in the area to date is an unbalanced use of quantitative approaches and lack of in depth use of case studies to form the basis of theorising in the area.

Some gaps are also identified pointing to the fact that issues concerning the extent of impact of cloud computing in SMEs have been ignored, whilst adoption is widely covered. To support in correcting these disparities in the literature, this paper identifies key research gaps relating to conceptual approaches, methodologies, issues addressed and finally provides pointers for future research directions.

Keywords: cloud computing, small and medium enterprises (SMEs), developing country, literature review

\section{Background and Rationale for the Review}

Cloud computing is viewed as an evolutionary advancement in computing in the last decade (Marston, Li, Bandyopadhyay, Zhang, \& Ghalsasi, 2011). Businesses and governments in the developed world are utilizing cloud computing to improve service delivery and performance. However, the picture is gloomy in some parts of the developing world, yet the potential is very high with the transformational nature of the cloud computing concept. The potential of cloud computing may have been doubted leading to the development of research models to explore its impact and potential. Truong (2009) is one of such researchers who used the resource based view theory to propose a research model exploring the impact of cloud computing resources on small business competitive advantages. Today, the story is not different in the developing world. Small businesses seem not to be fully utilising the cloud computing concept, though cloud computing offers a new way of rendering IT services as utility on a pay per use basis (Sultan, 2011) and changes the way computing services are invented, developed, deployed, scaled, updated, maintained and paid for (Marston et al., 2011).

In sub-Saharan Africa, cloud-related innovations and services are becoming fundamental sources of economic and societal change especially for economies that are embracing cloud computing (Kshetri, 2013). This is not different from other parts of the developing world like China, India and Taiwan (Chu et al., 2012; Kshetri, 2010, 2012; Lee \& Yen, 2012).

In the developing world, cloud computing is receiving a lot of attention from global and international agencies. Examples of these are the IBM establishment of cloud computing centers in China, India, Vietnam, Brazil, and South Korea. Other global bigwigs such as Microsoft, VMware, Salesforce, Dell, and Parallels are actively searching for opportunities in the developing world. Despite this global attention, the perception about the 
potential and impact of cloud computing in the developing world are confusing and remarkably inconsistent (Kshetri, 2010). Cloud does not only give developing economies the opportunity in terms of the same IT infrastructure, data centers, and applications to catch up with developed countries, but also offers low IT infrastructure costs and levels the playing field for SMEs (Kshetri, 2010) to compete with large companies.

In the developing world, cloud computing is still in its infancy (Kshetri, 2013). From a 2009 Gartner survey, half of the large businesses in emerging markets that were surveyed had not heard of cloud computing and had no idea what it represented. Cloud applications in the developing world are widely found in bigger economies like China, India, Brazil, South Africa, and Vietnam. Nonetheless, the cloud is gradually becoming popular and is being used in smaller economies (Kshetri, 2010).

Though cloud computing is seen as a nascent concept, it is not entirely new. The term cloud computing is new, but as Parkhill (1966) puts it, it is a new term for an age old ambition of computing as a utility. With its reliance on the internet and its relationship with virtualization and grid computing, cloud computing has foundations in ideas that are not new. Its current ubiquity is as result of the explosion of the Internet, increased bandwidth, mobile devices, and mobility requirements for users. There is a perceived inclination of micro and small businesses (SMEs or SMBs) toward cloud computing because of the benefits that could accrue to them. There are benefits for all kinds of business in the cloud environment, however, the needs and usage requirements of small businesses are different from large ones (Gupta, Seetharaman, \& Raj, 2013). This review leans towards this inclination. It takes a holistic approach to review the literature on small business involvement and engagement in cloud computing. The review looks at the issues from the conceptualization of cloud computing to adoption, migration, security and risk as well as performance enhancement. Whilst large business enterprises are adopting cloud computing (Klie, 2011; Li et al., 2011; Mahesh, Landry, Sridhar, \& Walsh, 2011), the story is different for micro businesses and SMBs. Small and Medium enterprises are still not convinced enough to move to the cloud in the developing world (Gupta et al., 2013).

This paper seeks to address the problem of non-existent literature reviews on the growing cloud computing paradigm and the place of small businesses in the ongoing debate. There are existing reviews on cloud computing research (El-Gazzar, 2014; Iyer \& Henderson, 2010; Venters \& Whitley, 2012; Yang \& Tate, 2012) but these are insufficient in the context of small business and different in the approach adopted by this review. First, Venters and Whitley (2012) in their review provides a framework of existing and future research on cloud computing. The framework is centered on a series of technological and service desires. Their review is based on the expectation or desires of potential cloud users as they adopt cloud services. This review, however, is based largely on what we know about cloud computing and SMEs, what we do not know and where we are headed with cloud computing research with a focus on small businesses in a developing country context. Second, Yang and Tate (2012) review is comprehensive and ground breaking, their review and that of the other reviews ignores the life cycle stage of applicability (that is whether the categorisation of research issues are each at development, adoption, use or impact level) and there is also no indication of the level of applicability (that is whether the categorization had any relationship with or was being discussed at the meta (global), Macro (national), Meso (sectoral) micro (organisational) or at individual user level)). Despite the need to build on previous reviews which have laid the foundation for future IS research on cloud computing, this review seeks to contribute in particular to cloud computing research in SMEs in DCs and IS as a discipline in general whilst acknowledging that the previous reviews (El-Gazzar, 2014; Venters \& Whitley, 2012; Yang \& Tate, 2012) provides the foundation and enough grounding to situate this review in the approach and context that it takes.

Thus, the overall aims of the review are as follows;

1) Conduct a review and analysis of the cloud computing literature on small and medium enterprises (SMEs) in developing countries (DCs)

2) Categorise and analyse the conceptual approaches for the understanding of cloud computing in DCs.

3) Categorise and assess the methodologies used to carry out the research and evaluate the evidence from the research.

4) Identify key research trends and gaps that relate to: a) concepts; b) methodologies; c) issues addressed and questions raised; d) evidence presented; and e) future research directions in the area.

This review is timely because given the rapid growth of cloud computing in the developed world as compared to the growing trends in the DCs, it is important to have an analysis of the literature to clearly present the state of SMEs in cloud computing in developing countries. A synthesis of the literature will expose how SMEs in developing countries are reaping the benefits cloud computing affords whilst addressing their challenges. This 
exposé will clearly indicate the research gaps that need to be filled whilst charting a research agenda for others in the future.

\section{Framing Cloud Computing Research}

\subsection{Cloud Computing Defined}

Cloud computing is a model of delivering a range of IT services remotely through the Internet and/or a networked IT environment (Sultan, 2013). The term 'cloud' is figurative and points to a large pool of usable resources such as hardware and software that are easily accessible through the Internet (Vaquero, Rodero-Merino, Caceres, \& Lindner, 2008; Vouk, 2008). Cloud computing offers computing services in a commoditised manner akin to utilities like water, electricity, gas and telephony. This is why cloud computing has been perceived as the fifth utility (Buyya, Yeo, Venugopal, Broberg, \& Brandic, 2009) because it provides the basic level of computing service for everyday use. There are many varied definitions of cloud computing in the literature and there is no standard and agreed definition of cloud computing used throughout the literature. For some definitions of cloud computing, the notion is that cloud service is offered by a third party. However, in providing a definition, Marston et al. (2011) tried to capture the key benefits of cloud computing from both a business perspective and a technological perspective by defining it as "an information technology service model where computing services (both hardware and software) are delivered on-demand to customers over a network in a self-service fashion, independent of device and location". Their definition takes cognizance of the fact that shared resources are needed and used in providing the services. The services are also dynamically scalable (Vaquero, Rodero-Merino, \& Buyya, 2011), rapidly provisioned (Zhang, Cheng, \& Boutaba, 2010), virtualized and released with minimal service provider interaction. Users of the cloud service in this direction pay for the service as an operating expenditure as opposed to the capital expenditure they would have incurred to either buy software or hardware components (Marston et al., 2011). The definitions are many. However, the most popular and widely used definition of cloud computing is that by the United States National Institute of Standards and Technology (NIST) that cloud computing is a 'model for enabling convenient, on-demand network access to a shared pool of configurable computing resources (e.g., networks, servers, storage, applications, and services) that can be rapidly provisioned and released with minimal management effort or service provider interaction' (Mell \& Grance, 2009; Mell \& Grance, 2011). The model consists of five essential characteristics, three service models, and four deployment models. The service and deployment models are discussed under the following section. However, the five essential characteristics of cloud computing are: Broad network access, on-demand self-service, rapid elasticity, measured service, and resource pooling.

\subsection{Description of Concepts}

As a utility, cloud computing must reach the end user through an outlet. However the type of outlet used to deliver cloud computing does not restrict the type of cloud computing service that is delivered. Four models are used to deploy cloud computing and through these models three main services can be delivered. Deployment Models: Cloud services are offered through four deployments models namely; private, public, community, and hybrid.

Private Cloud: In this type of cloud, the cloud infrastructure is managed solely for one organisations' use (Mujinga \& Chipangura, 2011b). It is an internal utilization of cloud technologies which is either maintained in-house or has restricted access to only users in the organisation (Yang \& Tate, 2012). It is also called an internal cloud.

Public Cloud: Here, the infrastructure is made available to the general public or an industry group. It is usually owned by cloud service providers (CSP) selling cloud services. It is hosted, operated, and managed by a third-party vendor from one or more data centers (Mather, Kumaraswamy, \& Latif, 2009). Some popular public cloud services are Amazon EC2 (Elastic Cloud), S3 (Simple Storage Service), Google AppEngine and SalesForce.com.

Community Cloud: This type of cloud infrastructure is communal and is used by several organizations. The different organisations usually have the same security needs and compliance requirements as well as a similar vision that may be managed by the organizations or a third party and may exist on premise or off premise (Marinos \& Briscoe, 2009; Mell \& Grance, 2011)

Hybrid Cloud: Typically, a hybrid cloud is made up of two or more clouds (private, community, or public).

Delivery Models: There are three cloud service delivery models to end-users. These are Infrastructure-as-a-Service (IaaS), Platform-as-a-Service (PaaS), and Software-as-a-Service (SaaS) (Mell \& Grance, 2011). Apart from these main service delivery models a number of variations are currently found in the 
literature. The coinage of everything as a service or X as a service (Xaas) as Schaffer (2009) puts it, has therefore come to stay. For clarity, the three main service delivery models are discussed below.

Software-as-a-Service (SaaS): provides a solution that utilizes servers, bandwidth, and software. This is offered and managed by the cloud service provider. With SaaS, an organization only looks for a provider that has the solution it needs and this solution must have already been tailored to its employees needs but the caveat is that the provider will ensure the service is always available (Siamak, 2010). Platform-as-a-Service (PaaS): A PaaS offers a hosted environment which is purely a web-based application-development platform that enables the development of programs online (Lawton, 2008). PaaS is built on top of Infrastructure-as-a-Service (IaaS) (Zhang et al., 2010) and provides the operating systems and services over the internet, eliminating the need to download or installs applications on end-user computers (Mujinga \& Chipangura, 2011b). Given this web-based development platform it means that PaaS is opened to developers who can use it to develop applications that can run on it (Giessmann, 2013).

Infrastructure-as-a-Service (IaaS): provides the whole infrastructure stack that supplies the computer infrastructure such as servers, memory, CPUs, disk space, and network connectivity (Mujinga \& Chipangura, 2011a) and enables technologies (Weinhardt, Anandasivam, Blau, \& Stosser, 2009).

Cloud computing and Small and Medium Enterprises (SMEs) in DCs: The term Small and Medium Enterprise (SME) has a wide range of definitions. The definition varies from country to country and different criteria are used to judge what an SME is. Whilst others have used the number of employees or total net assets, sales and investment level have also been used in some parts of the world. However, in all the varying definitions, the most common basis has been the number of employees, but even with that, there is a variation in defining the upper and lower size limit of the number of employees for an SME. Majority of sources define an SME as having a maximum of 250 employees (Ayyagari, Beck, \& Demirguc-Kunt, 2007). In view of the varied definitions of what constitute an SME, other terminologies have been used to describe small businesses in the literature. Some of these have been Small, Micro and Medium Enterprises (SMMEs), Small to Medium Businesses (SMBs).

SMEs are confronted with a lot of issues in their adoption of new technologies (Wang \& He, 2014) and its sustainability. This is because SMEs generally have limited resources making their adoption different from big businesses with more resources (Alshamaila, Papagiannidis, \& Li, 2013). However, given the constraints that SMEs face, cloud computing provides them with many opportunities such as flexibility, scalability, business agility and a pay-per-use option to deal with cost (Buyya et al., 2009; Iyer \& Henderson, 2010; Sultan, 2011; Venters \& Whitley, 2012).

\subsection{Classification of Cloud Computing Research}

Three criteria are used to classify cloud computing research. First, the classification takes into account previous research in cloud computing over the years. Cloud computing research can be classified based on the issue of interest. Venters and Whitley (2012) classifies these issues around some technological and service desires. These refer to the characteristics of the cloud that are important for cloud users. Yang and Tate (2012) on the other hand see these issues in four broad themes of technological, conceptual, domains and applications and business issues.

Whichever categorization is adopted, it is important to note that one can look at the technological issues or the technical aspects of the cloud that ensures the existence and functionality of the cloud on one hand and on the other hand, the business as well as the services the cloud provides. The business or services issues are reliant on the technical issues. This means that as the cloud offers many technological benefits it also offers sociological benefits (Yang \& Tate, 2012). Therefore, whilst cloud computing can ensure cheap on-demand computing power, better performance, reliability, and scalability (Erdogmus, 2009) to the business, it also offers low environmental cost in terms of better energy efficiency, compared to the traditional distributed enterprise data centers (Katz, 2009) which is a benefit to society.

Second, cloud computing research can be classified using the level of socio-economic analysis. This is what Heeks (2006) calls the level of applicability. These are the different levels at which cloud computing may be adopted and used. According to Walsham and Sahay (2006), these levels of analysis can be grouped into i) micro level to focus on the SMEs that use cloud computing application; ii) meso level to focus on the SMEs that serve as intermediaries to deliver cloud computing services; c) macro level to focus on SMEs that deliver the infrastructure, determine policy and set rules and regulations within which cloud computing applications can be adopted and used. 
Third, cloud computing research can be framed using the temporal method. This method is time dependent and involves the use of the 'informatics lifecycle or stage of applicability model' (Heeks, 2006) which proposes a four-stage lifecycle of development, adoption, use and impact. The level of analysis and the lifecycle of applicability are both adopted as part of the classifications in this review of cloud computing among SMEs in developing countries. Drawing on these, the review proposes the following four phases for the discussion of cloud computing in SMEs.

i) The readiness of SMEs in the clouds-Needs and Requirements.

This includes the needs of SMEs, requirements and desire to adopt cloud computing. These needs can be identified at various levels, for instance, the need for need for regulations and policy can be at the national, industry or even individual cloud consumer level. Literature that offers insight to these different levels of needs, requirements as well as the readiness of the SMEs are considered here.

\section{ii) The adoption and the processes of adoption of cloud computing by SMEs}

Studies that address the adoption of cloud computing by SMEs by presenting factors or determinants of SMEs adopt the cloud as well as studies that highlight the adoption process of SMEs, migration to the cloud, implementation and cloud integration issues with legacy IT systems are considered here. Processes of adoption include issues such as evaluation in terms of cost and cloud provider selection; adoption decision, integration and IT governance and usage and continuance issues.

iii) The use of cloud computing by SMEs

Adoption is not a necessary condition of usage. Studies that address how cloud computing is used by SMEs and the areas of usage are considered here.

\section{iv) The impact of cloud computing in SMEs}

Impact assessment involves studies that focus on identifying the anticipated or actual impacts of cloud computing in terms of factors such as the economic, environmental, efficiency and other management factors.

\section{Methodology for the Literature Review}

A literature review is an important aspect of determining what is known about a research issue, what is not known and the direction with which a research agenda is moving (Webster \& Watson, 2002). This review is conducted by targeting literature that reveals the currency of the state of IS research on cloud computing and small businesses in developing countries. To ensure its effectiveness and success, the review adopted and followed carefully the guidelines set out by some researchers (Levy \& Ellis, 2006; Vom Brocke et al., 2009; Webster \& Watson, 2002). This review was also done within some boundaries (Webster \& Watson, 2002). First, the review was conducted within the context of small and medium enterprises (SMEs) in the cloud and not individuals or the owners of the SMEs. The second was to limit the research articles addressing cloud computing in a developing country context. Only articles dealing with cloud computing as a core issue and dealing with small and medium sized businesses as well as other services in developing countries were included in the review. Thus, the search criteria cross referenced key words which are linked to (a) cloud computing (e.g., utility computing, Software as a service (Saas), Platform as a service (Paas), Infrastructure as a service (Iaas)) with those of (b) small businesses (e.g., Small and medium enterprises (SMEs), Small to medium businesses (SMBs), ) and those linked with the developing country context (e.g., developing countries, developed economies, low income countries). Another boundary was temporal, which encompassed cloud computing literature published between 2007 and 2014 in a diversity of journals focusing on cloud computing and SMEs until May 2014. Literature since 2007, the beginning of the cloud computing paradigm to date was targeted and this was because, cloud computing is a new concept the research on it is growing especially in the developing world. Developing country context literature is still scanty justifying why it was decided to go back to 2007.

\subsection{Scope of the Literature Search}

According to Vom Brocke et al. (2009), defining the scope of a review is the first step in the literature review process. The scope of this review has already been defined. This is what sets the stage for the literature search. Next was to identify where to locate the literature either through online platforms or manual searches of locations that contain journals of the relevant field. Cloud computing is new and is in its seventh year of existence. Though publication channels are still developing it was recommended to use online database searches as the primary sources since this approach has become an emerging culture among IS researchers interested in contemporary phenomena (Petter \& McLean, 2009; Sabherwal, Jeyaraj, \& Chowa, 2006) and was consistent with the steps by Vom Brocke et al. (2009). The actual literature search began with the identification of relevant 
journals and databases. Online databases were therefore used for this review. Consistent with Levy and Ellis (2006) the following online databases were identified and targeted:

1) AIS Electronic Library (AISeL),

2) ACM Digital Library,

3) IEEE Xplore,

4) Springerlink,

5) ScienceDirect,

6) EBSCOhost,

7) Wiley online library and

8) Google Scholar

These databases cover majority of IS journals and were considered comprehensive enough to gain a set of literature that represents the current status of IS research literature on SMEs in the cloud. To identify articles to be used in the review, keyword, abstract as well as title of article searches was conducted across the databases from 2007 with the phrase 'cloud computing'. Filters were used to restrict the searches to peer-reviewed and scholarly journals only. Conference papers, book chapters, books, thesis were all excluded.

Classification Scheme: Based on the existing literature reviews in cloud computing (El-Gazzar, 2014; Iyer \& Henderson, 2010; Venters \& Whitley, 2012; Yang \& Tate, 2012) and in other areas of IS (Boateng, Molla, \& Heeks, 2009) a classification scheme based on three broad thematic areas was adopted for this review. The thematic areas are potential and constraints, adoption and diffusion and support and implementation issues in cloud computing in SMEs. These were arrived at through a rigorous bottom-up approached influenced by the grounded theory (Wolfswinkel, Furtmueller, \& Wilderom, 2013) using open and axial coding. Though these three major categories were adopted, the classification did not entirely rely on that alone. Through open coding each article was coded and analyzed to tease out the themes that are captured in it. This led to several themes which were also labelled. Axial coding was then applied next to the identified and labelled themes to understand the relationships. This led to the categorization of the several sub themes into the three categories of potential and constraints, adoption and diffusion and support and implementation. Finally, selective coding technique was used to integrate and develop the relationships between the four categories. These also resulted in two main categories of technical issues and services issues in cloud computing among SMEs where the services (business and application areas) are largely dependent on the technical issues of the cloud.

To guide the understanding of the classification, each of the themes as adapted from a framework by Boateng, Molla, and Heeks (2009) are briefly explained below. Other classifications based on the theoretical or conceptual approaches and methodological approaches are discussed at other sections of this review.

Table 1. Classification framework

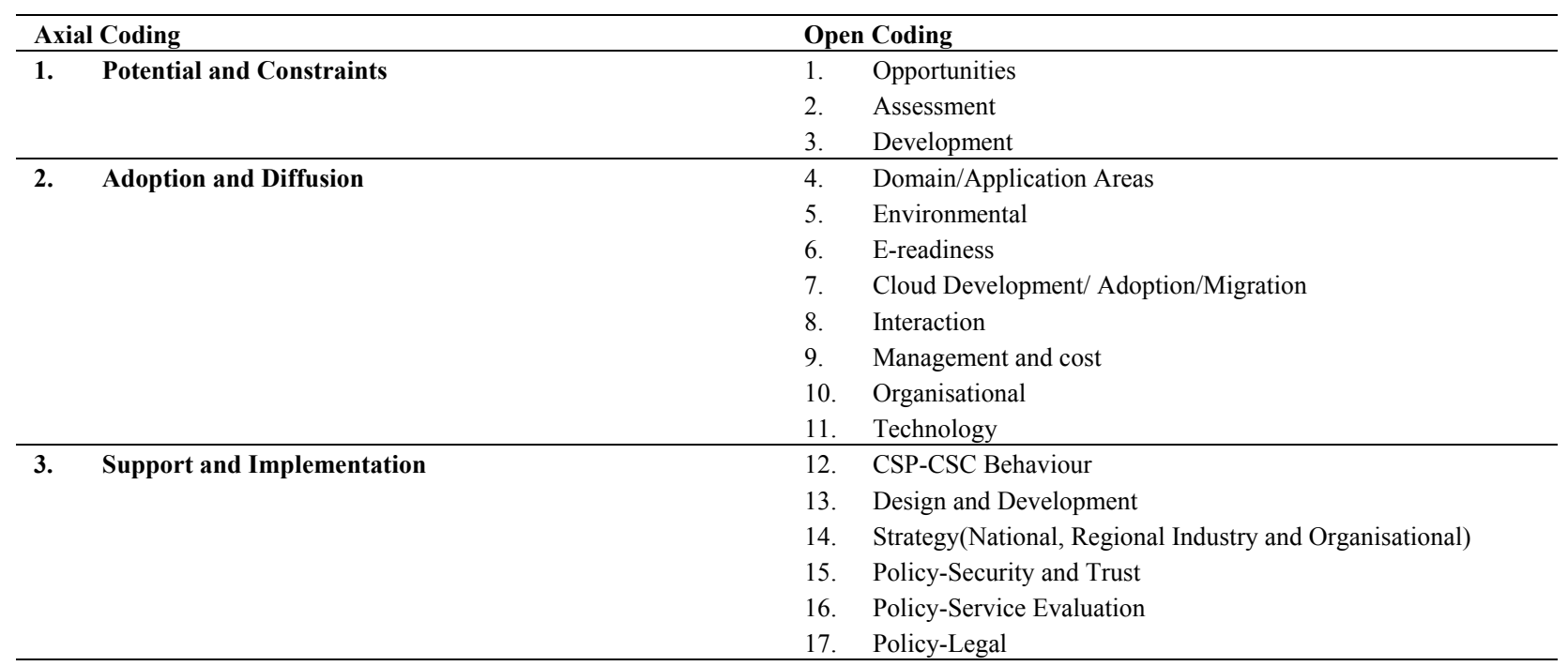

Adapted from Boateng et al. (2009) 
The coding scheme examines cloud computing research in the following phases:

- The fact that cloud computing is in its infancy in developing countries is supported by a literature that is largely characterized by diagnoses, prospects and the potential of cloud computing in developing countries. A discussion of the challenges and constraints of developing countries to tap the potential of the cloud is therefore considered here. In this direction a number of studies have focused on issues of the potential and challenges of cloud computing in developing countries (Kshetri, 2010; Kshetri, 2011; Kshetri, 2012, 2013) as well as factors determining the readiness of countries (UNCTAD, 2013).

- Cloud computing adoption and diffusion has also been an area that has featured widely in the literature (Behrend, Wiebe, London, \& Johnson, 2011; Kim, Kim, Lee, \& Lee, 2009; Low, Chen, \& Wu, 2011). Here, research has focused on a number of issues spanning the five domains of adoption, i.e., technological, managerial, organizational, environmental, and contextual and their linkages (Xu, Zhu, \& Gibbs, 2004)

- Finally, the success of adopting cloud computing in the developing world depends on a range of implementation issues such as strategy, consumer e-readiness, and support from cloud service providers and public policy. Hence, support and implementation is considered as a third theme of cloud computing research in developing countries.

Based on the above criteria, each of the 3 main criteria of the classification scheme is taken and its constituent elements discussed briefly in the following sections.

\section{Potential and Constraints}

The research discussing the benefits and constraints of cloud computing is conducted around three issues which form the sub themes. These are opportunities, assessment and development aspects of cloud computing

- Opportunities: this involves literature that discusses the potential benefit of cloud computing in developing countries. Some of the benefits are reduced costs for IT hardware and software; enhanced elasticity of storage and processing capacity, greater mobility of access to data and services; and enhanced reliability or security of data management and services (UNCTAD, 2013).

- Assessment: here the literature assesses the constraints to cloud computing implementation in developing countries and questions the conceptual and empirical evidence for propositions of the optimistic view (Pare, 2003). It also includes publications that specifically address e-readiness of developing countries at the national level.

- Development: literature that covers the impact of cloud computing on socio-economic development in developing countries.

\section{Adoption and Diffusion}

Here the literature that addresses technology, managerial, and organizational issues that will cause the adoption and diffusion of cloud computing were considered. These factors similarly affected the motivation the literature that was found here. These issues were grouped around:

- Cost and Management: the managerial aspect of adoption such as. Cloud computing pricing and other economic issues, negotiating service level agreements, cloud management and monitoring.

- Cloud Development/ Adoption/Migration: This section covers all the latest information on developing apps in the cloud, test and development in the cloud and the adoption of the cloud.

- Applications/Areas of cloud applications: This phase covers the type of cloud computing application or service discussed or researched in the literature. From the literature the cloud computing application areas currently being explored in developing economies were identified as consisting of six areas; e-education, e-health, e-commerce/e-business/ supply chain, e-governance, e-environment and telecommuting (N. Kshetri, 2010; Nir Kshetri, 2011).

\section{Support and Implementation}

Finally, this category consists of publications that cover support and implementation issues which influence the institutionalization of cloud computing after adoption. The sub themes covered in this category were divided into the following:

O Strategy: this covers the strategies employed by organizations, industries and nations in order to address the challenges of cloud computing so that they would be able to achieve the benefits cloud computing. Therefore all publications that discussed and looked at strategies that go beyond cloud computing adoption to determine the means of institutionalizing and embedding cloud computing into organizational processes to achieve its potential 
benefits.

- CSP-CSC Behavior: This is related to literature on issues about behavior in the use of cloud computing applications.

- Design and Development: the literature on technical development and migration support issues in relation to the implementation of cloud computing.

O Security: This covers areas of cloud security standards; how to manage data security in the cloud, data privacy in the cloud and the other dangers of moving to the cloud.

Filtering Process: The filtering process was largely done using EndNote. Throughout the search of the databases the references of the results that matched the search criteria were imported into EndNote database. When all the searches were completed and imported there were 176 articles. It was however, noted that some of the articles had no author names or were anonymous, existed in duplicates whilst though some related to cloud computing were related to more technical areas like computer science, engineering, biomedicine and so on. The 'find duplicate' function was used to remove duplicate references. In all 14 duplicates were removed. 20 articles without author names or designated as written by anonymous authors were also removed. The remaining articles which were 142 were then subjected to another process of filtering. This time, all the titles of the articles remaining in the EndNote database was manually scanned and all articles with irrelevant titles were removed. Here, articles that did not address cloud computing at all as a phenomenon in information systems and business were excluded. These also aided the processes of identifying further duplicates.

Next, the abstracts and the full text of the articles were reviewed in EndNote. This was after the articles were downloaded and attached to the corresponding reference in EndNote. All articles that did not address cloud computing as a main issue in its discussion but just mentioned it in passing in its discussion of other phenomena were removed. This was the most difficult and time consuming aspect of the analysis. Here, some book reviews, letters, briefs, and news items were identified and excluded because it had no academic insights. Some articles were also identified to have nearly the same contributions to the literature and written by the same authors. In such scenarios, the recent articles were used and the others deleted. 95 articles were left after this round of filtering.

Throughout the filtering process, the review was viewed as a sample, rather than a census of the cloud computing literature as of May, 2014. However, the review considers the sample as sufficiently broad and timely enough to represent many of the current and major theoretical and empirical discussions about the significance of cloud computing and SMEs in the developing country context.

\subsection{Presentation of Findings}

A total of 95 articles were reviewed and the findings are presented on the basis of article distribution over the period of the review, the outlets in which the articles were published, the distribution of articles over the business activities and the distribution of articles over the infrastructure and or applications in cloud computing among SMEs. The articles are initially analyzed in Table 2 by the percentage of the number of articles in the journals, and in Figure 1 by distribution of articles by year of publication. The classification categories in terms of distribution of articles by business activities, infrastructure and research focus are presented next in Tables 3, 4 and 5 respectively. These classification and presentation are consistent with classification and presentation schemes in previous reviews of cloud computing research (El-Gazzar, 2014; Iyer \& Henderson, 2010; Venters \& Whitley, 2012; Yang \& Tate, 2012).

\subsubsection{Distribution of Articles in Top IS Journals}

The number of articles published in each IS journal are presented in table 2. All the outlets are IS journals which are peer reviewed and do not include any conference paper. 
Table 2. Number of articles by journal

\begin{tabular}{lll}
\hline Journal & No. of Articles & \% \\
\hline International Journal of Information Management & 9 & 9.47 \\
IT Professional & 6 & 6.32 \\
Computer & 2 & 2.11 \\
Electronic Journal of Information Systems Evaluation & 2 & 2.11 \\
Expert Systems with Applications & 2 & 2.11 \\
International Journal of Cloud Applications and Computing (IJCAC) & 2 & 2.11 \\
Journal of Emerging Trends in Computing \& Information Sciences & 2 & 2.11 \\
Procedia Computer Science & 2 & 2.11 \\
Journal of International Technology \& Information Management & 2 & 2.11 \\
Procedia Technology & 1 & 1.05 \\
Computer Fraud \& Security & 1 & 1.05 \\
The Electronic Journal of Information Systems in Developing Countries & 1 & 1.05 \\
Third World Quarterly & 1 & 1.05 \\
Communications of the ACM & 1 & 1.05 \\
Communications of the Association for Information Systems & 1 & 1.05 \\
Decision Support Systems & 1 & 1.05 \\
International Journal of Management \& Information Systems (IJMIS) & 1.05 \\
International Journal of Research in Computer Application \& Management & 1.05 \\
Journal of Information Technology Theory and Application (JITTA) & 1 & 1.05 \\
Journal of Systems and Software & 1 & 1.05 \\
Journal of Technology Management for Growing Economies & 1 & 1.05 \\
Open International Journal of Informatics & 1 & 1.05 \\
Springer Computer Communications and Networks & 1 & 1.05 \\
Others & 1 & 54.74 \\
Total & 1 & $\mathbf{1 0 0 . 0 0}$ \\
\hline
\end{tabular}

Table 2 shows the percentage of total articles by selected journals, which consist of IS journals in general and some cloud computing journals. The 23 selected journals contribute to a little over $45 \%$ to the total number of journals, 43 articles. The journal with the highest percentage of articles is International Journal of Information Management, published by ScienceDirect. The IT professional is the second largest journal with $6(6.32 \%)$ of articles published by IEEE. Among the third largest number of articles with 2 articles each is the International Journal of Cloud Applications and Computing (IJCAC) established in 2011 published quarterly by IGI Global. The IJACC is the premier and an academic source for literature relating to aspects of Cloud Applications and Computing. This is the only top cloud computing journal with articles featured as part of the review

\subsubsection{Distribution of Articles by Year}

Figure 1 is an illustration of the interest in researching the issues of cloud computing and SMEs in DCs. The issues have risen exponentially from 2007 until 2013. This is an indication that SMEs in DCs are gradually embracing the cloud computing phenomena or it is becoming an interesting area for IS researchers. The 10 articles representing $10.5 \%$ of articles published in 2014 do not present a full picture of research on the subject for the year of 2014 because the only articles up to the end of May 2014 were considered for the review. There is a sharp increase in number of articles from 7 articles in 2010 to 23 articles in 2011 with slightly incremental number of articles in the two years following. The steep increase in number of articles is a result of sharp increase in the interest of IS researchers in the area of cloud computing as a results of the growing number of outlets in the area. 


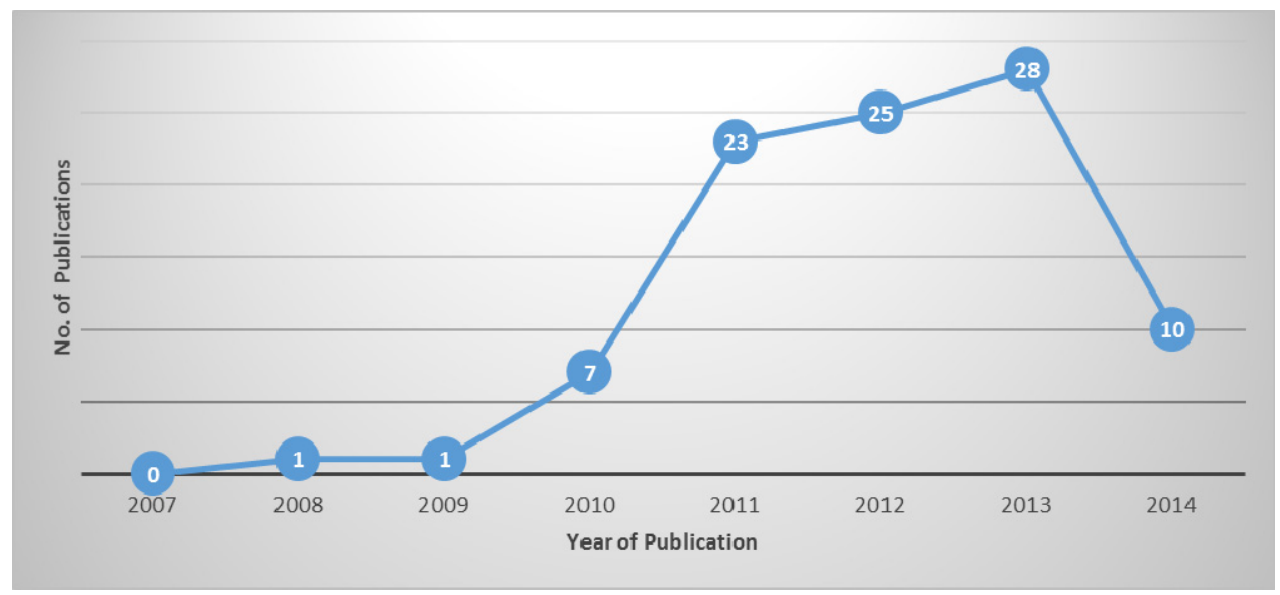

Figure 1. Distribution of Journal Articles by year

\subsubsection{Distribution of Articles by Business Activities}

The distribution of articles by issues and classification categories are presented in tables 3,4 and 5 respectively.

\section{Business Activities:}

The cloud can be viewed as both a technology and a business alternative (Iye, Krishnan, Sareen, \& Panda, 2013). As a technology it possesses some technical aspects which are critical not only to its existence but to its development, adoption and use. As a commercial alternative its cost, efficiency and management are important in its adoption and use by SMEs. It is in this direction that the classification here is based on technical (Technological) activities and business (service) activities in the cloud. The technical activities comprises of the technological and conceptual issues of the cloud (i.e. development, design, security etc.) whilst the business activities within and between CSPs, CSCs and regulators such as government consists of cost, benefits, management, application in health, education etc. are the services issues.

Service-oriented activities consisting of business activities between Cloud Service Providers and Cloud Service Consumers, Government and other regulators as well as within them has been the highest researched area with 40 articles (42\%) as indicated in table 3 below, in comparison with the application of the cloud in specific and/or general areas (33 article, $34.7 \%$ ). Therefore in terms of service oriented activities where the cloud is considered as a business alternative, the focus is on the interaction between CSPs and CSCs and how the cloud is managed by the consumer or the provider to reap its benefits. In DC, not very much research has been done in respect of the technical aspects. This is probably because awareness and how the benefits the cloud offers SMEs are not clearly embraced by many. Articles which centred on technological issues were $16(16.8 \%)$ whilst those that were targeted at gaining the conceptual understanding and awareness of the cloud were only $6(6.36 \%)$

Table 3. Number of articles by business activities

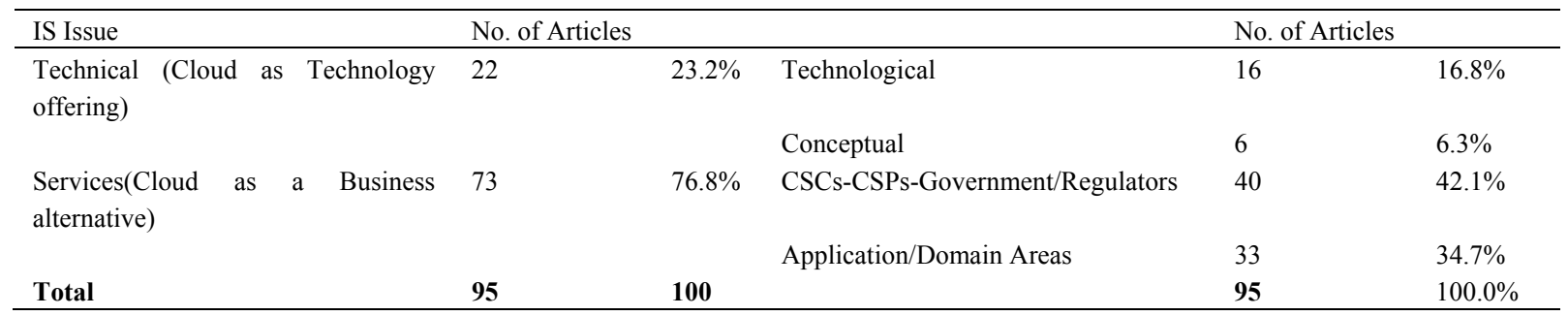

\subsubsection{Distribution of Infrastructure}

A lot of articles are focused on cloud computing applications or soft infrastructure. There are $35(37 \%)$ articles compared to $13(14 \%)$ articles representing the hard infrastructure. There is no considerable literature focusing on cloud application areas. This is evidenced by 5 articles in education, 1 e-governance, 4 financial services, 3 health, 4 manufacturing and 18 in all other general areas. The highest specific application area which was education was spread between Africa (Le Roux \& Evans, 2011) and Asia (Bhanti, Lehri, \& Kumar, 2011; Wang 
$\& \mathrm{He}, 2014)$. The research on the application of cloud computing in e-governance was on India (Rawal, 2011). With respect to financial services (Song, Shia, Yao, Wang, \& Fang, 2012), manufacturing (Huang, Li, Yin, \& Zhao, 2013) and health (Lai, Tam, \& Chan, 2012) the research was largely in Asia. Overall, there is not a lot of research on the technical aspects of the cloud in DCs as represented by $14 \%$ in table 4 . However, there is a lot of research on general issues about the cloud representing almost $50 \%$ of the research.

Table 4. Number of articles by infrastructure

\begin{tabular}{lllll}
\hline Cloud Infrastructure & & No. of Articles & Total & $\mathbf{\%}$ \\
Soft Infrastructure: Applications & & 35 & $37 \%$ \\
& Education & 5 & & \\
& E-governance & 1 & & \\
& Financial Services & 4 & & \\
& Health & 3 & & \\
& Manufacturing & 4 & & \\
& Others & 18 & 13 & $14 \%$ \\
Hard Infrastructure & & & 47 & $49 \%$ \\
General & & & $\mathbf{9 5}$ & $\mathbf{1 0 0 \%}$ \\
Total & & & & \\
\hline
\end{tabular}

\section{Research Focus}

The distribution of articles in Table 5 shows that majority of articles are focused on issues of potential and constraints (43 articles, 45\%), adoption and diffusion (31 articles, 33\%), and support and implementation (21 articles, 22\%). Within potential and constraints, a lot of articles are focused on opportunities (19 articles, 20\%) and assessment (13 articles, 14\%) compared with articles on development (10 articles, 11\%). The least research area here is how cloud computing can impact on DC economies generally and SMEs in particular and how this can be attained. How cloud computing can give SMEs in emerging markets a boost is well documented (Kshetri, 2010; Kshetri, 2013; Lee \& Yen, 2012; Murugesan, 2011).

With adoption and diffusion of cloud computing, the focus is on the application or domain areas where cloud computing is being used with a representation of 16 articles (17\%) is followed by the e-readiness of SMEs (6 articles, $6 \%$ ), the managerial aspects of adoption ( 4 articles, $4 \%$ ) and environmental issues ( 2 articles, $2 \%$ ). The knowledge gap lies in organizational determinants and interaction $(1 \%, 1$ articles) respectively. A study by Dahiru, Bass, and Allison (2014), explores the emergence and adoption of cloud computing by SMEs and directs attention towards its implications for DCs in sub-Saharan Africa.

The articles on support and implementation have focused largely on security and trust (7 articles, 7\%), CSP and CSC behaviour and relationships (5 articles, 5\%) and strategy issues (industry and organisational (4 articles, $4 \%$ ), national and regional (Helvacioglu-Kuyucu, 2011) (2 articles, 2\%)). The less-represented articles are on design and development as well as policy (service evaluation (Li, Zhang, O’Brien, Cai, \& Flint, 2013) (1 article) and legal issues (1 article).

The focus of future research on public policy issues can open opportunities for creating the confidence in adopting cloud computing in DCs. The lack of clarity of the legal issues of entering into a contract with a CSP to provide some cloud service for SMEs can be clearer if more research is done in this area. 
Table 5. Distribution of articles by research focus

\begin{tabular}{|c|c|c|c|c|c|}
\hline Research Focus & & No. of Articles & $\%$ & & \\
\hline \multirow[t]{4}{*}{ Potential and Constraints } & & & & 43 & $45 \%$ \\
\hline & Assessment & 13 & $14 \%$ & & \\
\hline & Development & 10 & $11 \%$ & & \\
\hline & Opportunities & 19 & $20 \%$ & & \\
\hline \multirow[t]{8}{*}{ Adoption and Diffusion } & & & & 31 & $33 \%$ \\
\hline & Domain Areas & 16 & $17 \%$ & & \\
\hline & Environmental & 2 & $2 \%$ & & \\
\hline & E-readiness & 6 & $6 \%$ & & \\
\hline & Interaction & 1 & $1 \%$ & & \\
\hline & Managerial & 4 & $4 \%$ & & \\
\hline & Organisational & 1 & $1 \%$ & & \\
\hline & Technology & 2 & $2 \%$ & & \\
\hline \multirow[t]{8}{*}{ Support and Implementation } & & & & 21 & $22 \%$ \\
\hline & CSP-CSC Behaviour & 5 & $5 \%$ & & \\
\hline & Design and Development & 1 & $1 \%$ & & \\
\hline & National and Regional Strategy & 2 & $2 \%$ & & \\
\hline & Organisational and Industry Strategy & 4 & $4 \%$ & & \\
\hline & Policy-Security and Trust & 7 & $7 \%$ & & \\
\hline & Policy-Service Evaluation & 1 & $1 \%$ & & \\
\hline & Policy-Legal & 1 & $1 \%$ & & \\
\hline Total & & 95 & $100 \%$ & 95 & $100 \%$ \\
\hline
\end{tabular}

\section{Mapping Cloud Computing Research: Issues and Evidence}

The mapping exercise conducted is a blend of several studies around using the stage of applicability and the level of analysis (Heeks, 2006) the combination of these two means that some literature overlaps from development, adoption, use and impact into research at the meta, macro, meso, micro and individual levels. Majority of articles span the adoption of cloud computing at the micro level, followed by requirements, needs and desire for cloud computing at the general DC (global) and the national or macro levels.

Only two studies deals exclusively with impact at the global (Meta) level and one at the National level. Few studies are found at either end of the lifecycle, with only 2 and 5 studies identified that looks at impact at the sectorial an organisational level with none at the individual levels. The research at the individual levels for development, adoption, use and impact are almost nil with only one study (Hadidi, 2011) at the development level.

The section below discusses the central issues in more detail according to the evidence presented in Table 6 .

Table 6. Mapping of articles reviewed according to a lifecycle stage of applicability and level of analysis

\begin{tabular}{|c|c|c|c|c|}
\hline \multirow[t]{2}{*}{ Stage of Applicability } & Development & Adoption & Use & Impact \\
\hline & $\begin{array}{l}\text { Articles on requirements, } \\
\text { needs and desires for } \\
\text { cloud computing }\end{array}$ & $\begin{array}{l}\text { Articles on areas of } \\
\text { adoption and application } \\
\text { of cloud computing }\end{array}$ & $\begin{array}{l}\text { Articles on use and } \\
\text { adaptation of cloud } \\
\text { computing }\end{array}$ & $\begin{array}{l}\text { Articles assessing } \\
\text { the impact of } \\
\text { cloud computing }\end{array}$ \\
\hline \multicolumn{5}{|l|}{ Level of Analysis } \\
\hline $\begin{array}{l}\text { Research at the Meta } \\
\text { level(Global) }\end{array}$ & $\begin{array}{l}29,30,31,49,50,64,68,73 \\
104,112\end{array}$ & $26,43,60,65,91$ & $58,71,74,101$ & 16,45 \\
\hline $\begin{array}{l}\text { Research at } \\
\text { Macro(National) level }\end{array}$ & $\begin{array}{l}14,18,22,35,51,52,61,67 \\
70,85,96\end{array}$ & $\begin{array}{l}57,59,63,76,78,97,98 \\
102,108\end{array}$ & 54,56 & 12 \\
\hline $\begin{array}{l}\text { Research at the Meso } \\
\text { (Sectoral) level }\end{array}$ & & 39,55 & $19,37,66,72,88,90,94,110$ & 20,29 \\
\hline $\begin{array}{l}\text { Research at the } \\
\text { Micro(Organisational) level }\end{array}$ & $\begin{array}{l}2,11,34,36,69,81,83,86, \\
99,105\end{array}$ & $\begin{array}{l}1,6,8,10,23,24,28,44 \\
47,75,79,93,95,107,109\end{array}$ & $\begin{array}{l}15,32,46,62,84,87,100,101, \\
103,106\end{array}$ & $3,9,21,41,92$ \\
\hline $\begin{array}{l}\text { Research at the individual } \\
\text { level }\end{array}$ & 33 & & & \\
\hline
\end{tabular}




\subsection{Identifying Requirements, Needs and Desires for Cloud Computing}

In the review 11 articles each were identified as dealing with the issue of SMEs requirements, needs and desire to adopt cloud computing at the general DC level across the globe, at the national level and at the organizational SME level. Only one article was identified at the individual level (Hadidi, 2011) with none at the sectorial level.

At the general SMEs level across the globe, some studies (Bunce, 2013; Goundar, 2010; Kshetri, 2011; Yeboah-Boateng \& Cudjoe-Seshie, 2013) were key in highlighting the benefit of the cloud to SMEs in DCs in particular and how DCs can generally benefit and manage. Particularly, Kshetri (2011) reviews cloud diffusion in DCs whilst examining some firms in presenting a framework for evaluating the attractiveness of the cloud in the context of their changing needs. Also, Murugesan (2011) analyses how cloud computing can give businesses access to advanced IT infrastructures and applications that might otherwise be out of their reach.

\subsection{Adoption and Application of Cloud Computing}

The research on adoption is low at sectorial level (Iye et al., 2013; Le Roux \& Evans, 2011) and non-existent at the individual level. It was however, highest at the organisational (micro) level (15 articles) followed by the general DC country at the global level.

At the organisational level issues such as the advantages, disadvantages and the inhibitors of cloud computing adoption by SMEs have been researched. Makena (2013) have researched the technological, organisational and environmental factors that have affected the adoption of cloud technologies in Kenya, the adoption and perception of cloud computing adoption by SMEs in South Africa (Hinde \& Van Belle, 2012) and the exploration of the of the motivation, enablers and inhibitors of the penetration of Cloud Computing in the Ghanaian ICT industry by Cloud Service Providers (Yeboah-Boateng \& Cudjoe-Seshie, 2013). Particularly of interest has been the study of Abdollahzadehgan, Gohary, and Amini (2013) on evaluating the impact of organizational factors on cloud computing adoption in SMEs using the TOE framework. This study supports SMEs in evaluating the critical success factors in adopting cloud computing.

At the sectorial level, the adoption issues were around how cloud vendors can be equipped with information regarding the relative risk perceptions of adopting cloud computing by SMEs vis-à-vis some inhibitors on a sector by sector basis (Iye et al., 2013) by positing that an understanding could help cloud computing vendors to improve product conceptualization and understanding to ensure more cloud consumers adoption of the technology.

\subsection{Assessment of Use and Adaptation of Cloud Computing}

In the assessment of the use and adoption of cloud computing by SMEs in DCs, the literature was skewed towards the micro (organisational) level with 10 articles and the meso (sectoral) level with 8 articles followed by research on DCs in general (4 articles ) and at the national level (2 articles). Literature at the individual level was nil.

In a paper by Werfs, Baxter, Allison, and Sommerville (2013) where an SME was moving to the cloud, adaptive socio-technical systems (ASTSs) concepts were used to provide a framework to aid the understanding of the adoption process. They used a set of macro and micro themes in relation to three key phases of strategy development, the migration process and the impact on customer perceptions. Under the one of the macro themes of strategy for the cloud and using interviews they discovered that there was no clear strategic driver (micro theme) for the use of cloud computing and that the cloud adoption decision was as a result of the recognising the benefits and dangers of not adopting it. The adoption here was therefore that of technology push than a market pull, where the pressure to adopt cloud computing would come from the customers. Gupta et al. (2013) presents five factors that are key in influencing the cloud usage by SMEs by emphasizing that the business requirements of SMEs are different from large ones. They posit that whilst the ease of use and convenience is the most favorable factor in cloud adoption by SMEs followed by security and privacy, cost reduction and reliability. However, they concluded that, SMEs do not want to use the cloud for sharing and collaboration. Instead SMEs prefer the traditional methods for sharing and collaborating with their stakeholders. At the sectorial level, adoption and usage has been researched by Christauskas and Miseviciene (2012) indicating that cloud accounting systems for SMEs presents great opportunities in saving a lot of funds. The use of cloud computing in health care and education has also been explored (Sultan, 2010, 2014) as well as in human resource management (Peterson, 2012). At the national level, usage in Asia, particularly in China and Taiwan has been prominent (Lai et al., 2012; Lee \& Yen, 2012). 


\subsection{Assessment of Impact of Cloud Computing}

The review turned up ten articles in all for impact studies at the four levels of analysis. The literature at the micro level was highest with 5 articles dealing with SMEs at the organisational level. Jianzhen (2011) discusses the opportunities and challenges of cloud computing for the development of SMEs. They conclude that whilst the application of cloud computing in SMEs is feasible, it is its proper implementation that can bring value to SMEs. Azarnik, Shayan, Alizadeh, and Karamizadeh (2012) on the other hand, explores the associated risk of cloud computing by SMEs whilst they enjoy its benefits. This is an indication that the cloud may have some unintended consequences in terms of security failures.

\section{Conceptual Approaches and Methodological Issues in Cloud Computing Research}

In this section the conceptual and methodological approaches taken in the review are categorised and analysed. This provides the basis for the identification of the gaps in methodologies and conceptual approaches presented in Section 6 of this review.

Table 7. Mapping of articles surveyed according to conceptual and methodological approach taken

\begin{tabular}{|c|c|c|c|c|}
\hline & $\begin{array}{l}\text { Approaches inspired by } \\
\text { Social }\end{array}$ & $\begin{array}{l}\text { Approaches inspired by } \\
\text { Social-theories/models }\end{array}$ & $\begin{array}{l}\text { Approaches } \\
\text { inspired by } \\
\text { Technical Theories }\end{array}$ & $\begin{array}{l}\text { No Defined Theoretical } \\
\text { Approach }\end{array}$ \\
\hline Quantitative & $57,75,104$ ( 3 articles) & $\begin{array}{l}6,14,32,39,58,59,61,78,84 \\
87(10 \text { articles) }\end{array}$ & & $\begin{array}{l}15,26,44,76,85,87,105,108 \\
\text { ( } 3 \text { articles) }\end{array}$ \\
\hline Qualitative & $66,109$ ( 2 articles $)$ & $\begin{array}{l}29,36,54,60,63,97,100,101 \\
102,107 \text { (10 articles) }\end{array}$ & & $11,86,88,90,91$ ( 8 articles $)$ \\
\hline Mixed & & & & 1,93,112 (3 articles) \\
\hline $\begin{array}{l}\text { Descriptive: No Defined } \\
\text { Methodological } \\
\text { Approach evident }\end{array}$ & $24,50,79$ (3 articles) & $\begin{array}{l}35,43,47,56,62,64,65,69,70 \\
, 83,99,106(\mathbf{1 2} \text { articles) }\end{array}$ & 37 & $\begin{array}{l}2,3,8,9,10,12,16,18,19,20,2 \\
1,22,23,28,30,31,33,34,41, \\
45,46,49,51,52,55,67,68, \\
71,72,73,74,76,81,92,94, \\
\text { 95,96,98,99,103,110 } \\
\text { (41articles) }\end{array}$ \\
\hline
\end{tabular}

\subsection{Conceptual Approaches}

Initially in Table 7, a categorisation of the conceptual approaches were done using a criteria of social, socio-technical, technical theories as well as literature that did not employ any theory at all. This, though broad, provided an initial insight on the understanding and the spread of a diversified conceptual approaches in the literature.

In all, 55 articles did not use any theory and only one study was backed by technical concepts. 32 studies were backed by socio-technical theories or models whilst 8 were identified as influenced by purely social theories. A detailed analysis of the conceptual approaches used in the cloud computing research in SMEs in DCs is provided in Table 8. The table presents the key research approaches grouped in line with the categorisation of issues made using the life cycle or the stage of applicability model. The review identified 23 articles with key references to their previous research (antecedents) cited in the study in which the conceptual approach was based. To make for a clearer understanding, the conceptual approaches are further distinguished using an adapted outline (Duncombe \& Boateng, 2009; Heeks \& Bailur, 2007). The outline makes use of a hierarchy of narrower conceptualisations to a deeper theoretically-based approache. This involves:

- $\quad$ Theory-based approaches: which employ an identifiable theory

- Framework-based approaches: which employs a framework for analysis with basis from a body of theoretical work

- Model-based approaches: models that are used, but without reference to an identified body of knowledge

- Concept-based approaches: this makes use of a defined concept though the concept is not theoretically grounded 
Table 8. Mapping of conceptual approaches to the research on cloud computing in SMEs in DCs

\begin{tabular}{|c|c|c|c|c|}
\hline Research Issue & Conceptual Approaches Identified & $\begin{array}{l}\text { Classification of } \\
\text { Conceptual } \\
\text { Approaches }\end{array}$ & Antecedents Cited & Article \\
\hline \multicolumn{5}{|l|}{ Development } \\
\hline \multirow{7}{*}{$\begin{array}{l}\text { Articles on } \\
\text { requirements, needs } \\
\text { and desires for } \\
\text { cloud computing }\end{array}$} & General Categories of Decision Buttons & Model & Van Schendelen (2003) & 35 \\
\hline & Benefit-Threat Framework & Framework & None & 61 \\
\hline & SWOT Framework & Framework & None & 64 \\
\hline & The virtual enterprise Model & Model & None & 69 \\
\hline & $\begin{array}{l}\text { The Business Cloud Cube Model (CCM) used to classify } \\
\text { the cloud computing business model in } 8 \text { (eight) } \\
\text { categories. }\end{array}$ & Model & $\begin{array}{l}\text { Chang, Bacigalupo, } \\
\text { Wills, and De Roure } \\
(2010)\end{array}$ & 70 \\
\hline & $\begin{array}{l}\text { SOURCER framework. The framework introduces a } \\
\text { methodology and decision-making criteria that will assist } \\
\text { end-user organisations with the selection of ICT services } \\
\text { in order to maintain and manage a most suitable ICT } \\
\text { service portfolio. }\end{array}$ & Framework & (Sebesta, 2010) & 83 \\
\hline & $\begin{array}{l}\text { Information Services Architecture for SMEs using Cloud } \\
\text { Computing }\end{array}$ & Model & None & 99 \\
\hline \multicolumn{5}{|c|}{ (2: } \\
\hline \multirow{11}{*}{$\begin{array}{l}\text { Articles on areas of } \\
\text { application and } \\
\text { adoption of cloud } \\
\text { computing }\end{array}$} & ICT Lifecycle Model & Model & None & 6 \\
\hline & $\begin{array}{l}\text { A framework to evaluate the attractiveness of cloud } \\
\text { computing in the context of evolving needs, capabilities } \\
\text { and competitive positions. }\end{array}$ & Framework & Bhagwati (1998) & 62 \\
\hline & $\begin{array}{l}\text { i) The two-factor theory to classify the SaaS market } \\
\text { into adoption-driving and adoption-inhibiting areas. } \\
\text { ii) PEST Analysis- a method for analysing markets } \\
\text { and business environments by considering various } \\
\text { political, economic, social and technological factors }\end{array}$ & Theory & $\begin{array}{l}\text { Herzberg et al. (1959) } \\
\text { Fahey and Narayanan } \\
(1986)\end{array}$ & 57 \\
\hline & $\begin{array}{l}\text { The TOE (Technology-Organization-Environment) } \\
\text { framework and HOT-fit } \\
\text { (Human-Organization-Technology fit) model }\end{array}$ & $\begin{array}{l}\text { Framework } \\
\text { Model }\end{array}$ & $\begin{array}{l}\text { Tornatzky \& Fleischer } \\
(1990) \\
\text { Yusof, Kuljis, } \\
\text { Papazafeiropoulou, \& } \\
\text { Stergioulas(2008) } \\
\end{array}$ & 59 \\
\hline & The Diffusion of Innovation Theory & Theory & Rogers (1995) & 60 \\
\hline & TOE Framework & Framework & $\begin{array}{l}\text { Tornatzky \& Fleischer } \\
\text { (1990) }\end{array}$ & 63 \\
\hline & $\begin{array}{l}\text { Institutional theory } \\
\text { Unified Theory of Acceptance and Use of Technology } \\
\text { (UTAUT) }\end{array}$ & Theory & $\begin{array}{l}\text { Gholami et al. (2013) } \\
\text { Venkatesh et al. (2003) }\end{array}$ & 75 \\
\hline & $\begin{array}{l}\text { Proposed a solution framework that employs a modified } \\
\text { DEMATEL approach to cluster a number of criteria } \\
\text { (perceived benefits and perceived risks) into a cause } \\
\text { group and an effect group, respectively. }\end{array}$ & Framework & $\mathrm{Wu}(2011)$ & 78 \\
\hline & Service strategy matrix of cloud service providers. & Framework & None & 97 \\
\hline & TOE Framework & Framework & $\begin{array}{l}\text { Tornatzky, Fleischer, \& } \\
\text { Chakrabarti (1990) }\end{array}$ & 107 \\
\hline & Grounded Theory & Theory & $\begin{array}{l}\text { Glaser and Strauss } \\
(1967)\end{array}$ & 109 \\
\hline \multicolumn{5}{|l|}{ Use } \\
\hline \multirow{5}{*}{$\begin{array}{l}\text { Articles on use and } \\
\text { adaptation of cloud } \\
\text { computing }\end{array}$} & $\begin{array}{l}\text { Knowledge as a Service (KaaS) model that facilitates the } \\
\text { interoperations among members in a knowledge network. }\end{array}$ & Model & None & 54 \\
\hline & Cloud Development Framework & Framework & None & 56 \\
\hline & Service Oriented Architecture(SOA)-Base Model & Model & None & 84 \\
\hline & Financial Crisis Risky model & Model & None & 87 \\
\hline & $\begin{array}{l}\text { The concept of adaptive socio-technical systems (ATS); } \\
\text { an approach to describe the changing world and used as } \\
\text { an analytical framework to study how companies } \\
\text { transform their products to cloud-based services }\end{array}$ & Concept & Werfs et al. (2013) & 101 \\
\hline
\end{tabular}


Literature that employ theoretically-based approaches were largely social theories, though this differed according to the level of analysis. At the level of adoption of cloud computing Lee, Chae, and Cho (2013) used a two-factor theory to classify the SaaS market into adoption-driving and adoption-inhibiting areas and also employing PEST analysis to investigate the factor that has the most significant influence on the adoption drivers and adoption inhibitors of cloud computing. They then apply the market segmentation and PEST analysis to an analytic hierarchy process (AHP), proposed by Saaty (2004). The AHP is a structured technique for analysing complex decisions. The AHP compares each factor in pairs and then estimates its importance (Saaty, 2004).

Lin and Chen (2012) employed the diffusion of innovation theory as the theoretical basis to underpin the identification of the factors encouraging and preventing cloud adoption. The study used an interview approach to understand IT professionals' understandings and concerns about cloud computing. The findings of the study suggested that while the benefits of cloud computing such as its computational power and ability to help companies save costs are abound in the literature, the primary concerns that IT managers and software engineers have are compatibility of the cloud with companies' policy, IS development environment, and business needs; and relative advantages of adopting cloud solutions.

Further, Ramayah, Siew, Ahmad, and Halim (2013) employed institutional theory to explain how the influence exerted by internal and external factors unto firms induce their practices overtime. Therefore, the institutionalization of Green IT practices among early adopters such as multinational corporations can be easily transferred or imitated by firms who are experiencing the pressure to reduce environmental impacts of their operating activities. The study also employed the unified theory of acceptance and use of technology (UTAUT)'s (Venkatesh, Morris, Davis, \& Davis, 2003) facilitating conditions as one of the determinants of UTAUT model and analysed its influence on Green IT implementation. The study showed that SMEs are receptive towards the implementation of Green IT practices. The study also showed that external factors, such as coercive and mimetic pressures, and internal factors, such as facilitating conditions, are important drivers that encourages SMEs to adopt green practices.

There is no extensive use of theory in the early stages of the cloud computing literature and only few sources have been identified as indicated in Table 7. Narrower theories in the form of framework based approaches are more widespread. Out of the 23 studies considered here 9 articles were identified as framework based. These included the Benefit-Threat Framework by Mahara (2013) on economical, technological and people perspective that an SME perceives while selecting ERP in cloud environment. The framework suggests that economic and technological are two important perspectives while selection of ERP on cloud for a SME.

Mahesh, Landry, Sridhar, and Walsh (2011) uses a framework for evaluating the attractiveness of cloud computing in the context of evolving needs, capabilities and competitive positions by drawing on Bhagwati (1998) theory of kaleidoscope competitiveness. The use of the TOE (Technology-Organization-Environment) framework (Tornatzky et al., 1990) has been dominant among the frameworks employed in the 9 studies. Lian, Yen, and Wang (2014) have used it alongside the HOT-fit (Human-Organization-Technology fit) model to explore the critical factors that affect the adoption of the cloud in a Taiwanese hospital. Gathering data through a questionnaire research design, the study revealed that the 5 most critical factors in deciding whether to adopt the cloud are data security, perceived technical competence, cost, top manager support, and complexity. Also, they proposed four dimensions of technology followed by human, organizational, and environmental factors as key and concluded that significant differences exist in CIO innovativeness, data security, compatibility, top manager support, adequate resource, and perceived industry pressure across different adopting groups. In the same direction, Makena (2013) has used the same framework to explore adoption factors in Kenyan SMEs.

Out the models identified, the Information Services Architecture for SMEs using Cloud Computing model by H. Wang (2013), the ICT lifecycle model by Alena and Libor (2012), Service Oriented Architecture(SOA)-Base Model by Seth, Agarwal, and Singla (2012) and the Financial Crisis Risky model (Song et al., 2012) were key. The concept of adaptive socio-technical systems (ATS) was identified as an analytical lense used to study how companies transform their products to cloud-based services (Werfs et al., 2013). 


\subsection{Methodological Issues}

Table 9. Mapping of articles surveyed according to conceptual and methodological approach taken

\begin{tabular}{lllll}
\hline & $\begin{array}{l}\text { Approaches inspired } \\
\text { by Social Theories }\end{array}$ & $\begin{array}{l}\text { Approaches inspired by } \\
\text { Social-theories/models }\end{array}$ & $\begin{array}{l}\text { Approaches inspired by } \\
\text { Technical Theories }\end{array}$ & $\begin{array}{l}\text { No Defined Theoretical } \\
\text { Approach }\end{array}$ \\
\hline Quantitative & $57,75,104$ & $6,14,32,39,58,59,61,78,84,87$ & $15,26,44,76,85,87$, \\
& & & 105,108 \\
Qualitative & 66,109 & $29,36,54,60,63,97,100,101$, & $11,86,88,90,91$ \\
& & 102,107 & \\
Mixed & & $35,43,47,56,62,64,65,69,70$, & 37 & $1,93,112$ \\
Descriptive: No Defined & $24,50,79$ & $83,99,106$ & $2,3,8,9,10,12,16,18,19,20$, \\
Methodological & & & $21,22,23,28,30,31,33,34$, \\
Approach evident & & & $41,45,46,49,51,52,55,67$, \\
& & & $68,71,72,73,74,76,81,92$, \\
& & & $94,95,96,98,99,103,110$ \\
\hline
\end{tabular}

Out of the total literature sources surveyed, over $60 \%$ (66 articles) were purely descriptive without any evident and defined methodological approach. This notwithstanding, it provided a lot of insight and direction of SMEs in the cloud in DCs. The potential and barriers of cloud adoption in DCs has generally been explored by some of these studies (Cheng-Chung Chu et al., 2012; Kshetri, 2010, 2012, 2013; Mujinga \& Chipangura, 2011; Mujinga, 2012; Wai-Ming, Lai, \& Chung, 2013) whilst some have concentrated on the potential, advantages, disadvantages barriers to its adoption by SMEs (Ahmad \& Siddiqui, 2013; Azarnik, Shayan, Alizadeh, \& Karamizadeh, 2012; Emm, 2013; Jianzhen, 2011; Karabek, Kleinert, \& Pohl, 2011; Scott, 2012).

Whilst the sources have all provided snippets of descriptive analysis of SMEs in the cloud, much of such literature is concentrated in Asia with only a few in Africa. 16 articles purely employed quantitative studies with three mixed method approaches (Abdulkader \& Abualkishik, 2013; Trigueros-Preciado, Pérez-González, \& Solana-González, 2013; Yeboah-Boateng \& Cudjoe-Seshie, 2013). Yeboah-Boateng \& Cudjoe-Seshie (2013) provided an insight into the Cloud computing eco-system in Ghana, a DC country as case example and revealed that there is positive experience with the cloud computing model from the consumer standpoint. Qualitative research was most dominant with 20 articles. Studies such as Dahiru, Bass, \& Allison (2014) collected data through open-ended face-to-face semi-structured interviews and supported by observations. The study found that, contrary to the literature on cloud computing adoption in SMEs, the SMEs are less concerned with challenges like security, privacy and data loss rather but show optimism in using the potential opportunities that cloud computing presents to them.

Lai, Tam, \& Chan (2012) uses a qualitative case study to show the best practices of the formation of collaborative network facilitation by a knowledge cloud system in the medical service industry in China. Shukla, Agarwal, \& Shukla (2012) also employed case studies of three manufacturing industries and show the benefits of the implementation of the Cloud based ERP. Wu, Lan, \& Lee (2011) also uses case study to explore factors affecting an organisation's SaaS adoption. The use of the case study approach is popular in these qualitative studies and provides understanding of valuable insights into cloud adoption by SMEs there is a noticeable lack of in-depth qualitative case studies that could provide a basis for theorising.

\subsection{Geographical Distribution}

This section focuses on the geographical distribution of current research on cloud computing in SMEs in DCs. The distribution indicates that the literature reviewed is mostly concentrated on issues that do not have a geographical specificity (43\%). This supports the widespread descriptive nature of the literature surveyed instead a concentration on a particular location. Asia is the most represented region (29\%). The rest are Europe (14\%), Africa (9\%), and North America (2\%). 


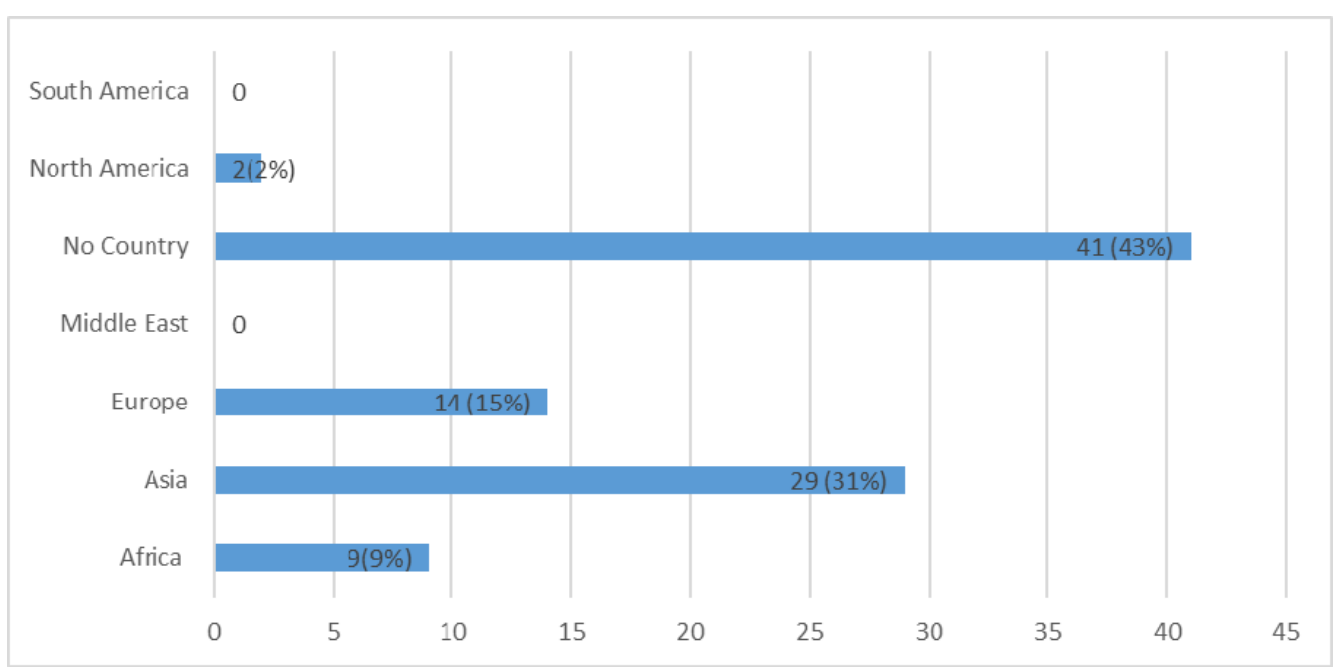

Figure 2. Distribution of cloud computing research by geographic region

Within these regions, differences occur in the area that is focused by the literature. In Africa, the issues are mainly awareness of the cloud and its adoption by SMEs (Dahiru et al., 2014; Yeboah-Boateng \& Essandoh, 2013). In Asia however, apart from the discussion of the benefits of the cloud as is discussed in the Africa literature, there are clear areas of the application of cloud computing in SMEs (Lai et al., 2012; G. Wang \& Unger, 2013), a clear attestation of how this technology is being used and the benefits that are accruing to businesses in these areas. The discussion in Europe is more advanced with issues such as contractual issues (Budniks \& Didenko, 2014; Hon, Millard, \& Walden, 2013) as well as data governance issues (Begg \& Caira, 2010). In Africa, the dominant countries are Ghana (Yeboah-Boateng \& Cudjoe-Seshie, 2013; Yeboah-Boateng \& Essandoh, 2013), South Africa (Hinde \& Belle, 2012; Le Roux \& Evans, 2011) and Kenya (Makena, 2013; Mujinga, 2012). In taking a closer look, the author examines the distribution of cloud computing in SMEs within Africa comparing the level of analysis and motivation of the research.

Table 10. Mapping of articles on Africa according to issues and level of analysis

\begin{tabular}{|c|c|c|c|c|}
\hline Stage of Applicability & Development & Adoption & Use & Impact \\
\hline & $\begin{array}{l}\text { Articles on requirements, needs } \\
\text { and desires for cloud } \\
\text { computing }\end{array}$ & $\begin{array}{l}\text { Articles on areas of } \\
\text { adoption and application } \\
\text { of cloud computing }\end{array}$ & $\begin{array}{l}\text { Articles on use } \\
\text { and adaptation of } \\
\text { cloud computing }\end{array}$ & $\begin{array}{l}\text { Articles assessing } \\
\text { the impact of } \\
\text { cloud computing }\end{array}$ \\
\hline \multicolumn{5}{|l|}{ Level of Analysis } \\
\hline $\begin{array}{l}\text { Research at the Meta } \\
\text { (Global) level }\end{array}$ & & & & \\
\hline $\begin{array}{l}\text { Research at the Macro } \\
\text { (National) level }\end{array}$ & 52,67 & $63,108,112$ & & \\
\hline $\begin{array}{l}\text { Research at the Meso } \\
\text { (Sectoral) level }\end{array}$ & & 55 & & \\
\hline $\begin{array}{l}\text { Research at the Micro } \\
\text { (Organisational) level }\end{array}$ & 69 & 109 & 62 & \\
\hline
\end{tabular}

As shown in Table 10, there is no fair representation of empirical studies in the research area on Africa. Overall, only nine studies were identified in the survey of the literature. Majority of the studies are at the macro level (5 articles) discussing areas where cloud computing could be used in DCs (Kshetri, 2013), cloud security (Mujinga, 2012), the adoption and perception of cloud computing by SMEs (Makena, 2013) as well as the emergence of ASPs in DCs (Yeboah-Boateng \& Cudjoe-Seshie, 2013). At the meso level (Le Roux \& Evans, 2011) discusses cloud computing applications and services currently used by secondary education in DCs and how it can be used to help bridge the digital divide that currently exists in the secondary (basic) education sector in South Africa. At the micro level, Mvelase, Dlodlo, Williams, and Adigun (2011) proposes the use of a virtual enterprise enabled cloud enterprise architecture based on the concept of virtual enterprise at both business and technology levels to enable SMEs to increase productivity and gain competitive advantage due to the cost benefit incurred. The 
discussion at the Africa level points to a concentration of literature at the macro and micro levels and supports the view that that as cloud computing evolves, more SMEs in Africa will adopt it as an IT Strategy (Dahiru et al., 2014) and eventually SMEs can effectively contribute to economic growth in DCs.

\section{Research Gaps and Future Research Directions}

In this section, the key research developments and gaps in accordance with the issues and evidence, the theoretical and methodological approaches used in the review process. The last part of the section presents some pointers for future research directions in the area.

\subsection{Gaps in Issues and Evidence}

With reference to the stage of applicability or the lifecycle approach, the concentration of research has been at the requirements, needs and desires for cloud computing at the DC level across the world. There is scanty evidence of impact at the same level, an indication that the adoption and use of cloud technologies in SMEs in particular and in DCs generally have not reached the stages where evidence of how cloud computing has impacted on business is clearly evident. However, a couple of studies have discussed the potential impact at this level. The national level also portrays such a gloomy picture of impact. Research at the micro level is dominant with much evidence at the lifecycle model continuum. Here research on impact is greatest for all the levels of analysis. Despite the wide discussion of the requirements and needs, adoption, use and impact of cloud computing in SMEs in DCs, tracing the adoption process of SMEs from the usage of traditional computing to its adoption of the cloud paradigm is missing. The migration process of SMEs to the cloud and how this impacts existing process and the sustainability of the business has is completely missing. Only one study investigated how a set of SME high-value software vendors are migrating their software products to the cloud (Werfs et al., 2013) using Adaptive socio-technical systems (ASTSs) concepts to provide a framework for understanding the adoption process. Adoption effects and impact on the individual SMEs customers as well as staff has not been covered. The closest have been a study on what the managers of SMEs need to know (Hadidi, 2011).

At the micro level, a majority of studies also highlighted the offering of cloud computing as a service as opposed to the technological underpinnings and understanding. This included awareness, application areas and the benefits and management issues of cloud by SMEs. This is in agreement with the view of cloud computing as a business model or opportunity and a technology offering as well (Iye et al., 2013). The level of studies concentrating on cloud computing in SMEs in DCs as a technology other than a service was few, an indication that the services offered by the cloud is what is driving SMEs drive to adopt it and not other pressures or influences.

In particular, not much research was seen in the area of support and implementation for cloud adopters and/providers. This was particularly evident in the lack of studies on policy issues on cloud service evaluation, legal issues and clarity on security issues for SMEs. This could possibly be due to the absence of national and industry strategies to guide the cloud adoption and management issues in DCs. The CSP-CSC behaviour and relationships are not much researched given the fact that the relationship between Application Service Providers (ASPs) or CSPs and CSCs relationships are completely different from traditional outsourcing relationships between a supplier and a vendor.

Some gaps were identified in relation to geographical focus. A lot of the research focused on, and draw examples from cloud computing initiatives located in Asia with quite a few on Africa and a majority indicating no geographical location. The lack of geography in a lot of the studies could be as a result of the descriptive nature of many studies.

\subsection{Gaps in Conceptual Approach}

Cloud computing research in DCs in the area of needs and requirements, adoption, usage and adaptation are much conceptualised. This conceptualisation draw on IS research approaches which provide a good foundation to facilitate and develop future research. However, the extent of research on the impact of cloud computing in SMEs in DCs is not well defined and researched conceptually. Throughout the review, no defined framework or theory was identified for the understanding of the impacts of this emerging technology for SMEs in DCs who stand to gain considerable from this computing paradigm. This may be the fact that SMEs in DCs advantages of cloud adoption are well documented, a longitudinal study to understand the impact from adoption to impact is missing. The absence of literature on concept, frameworks or theories assessing the impact supports this view. The use of theory such as the diffusion of innovations, institutional theory and the TOE framework gives emphasis to why cloud computing is adopted by SMEs. There is lack of theory on why and how it is used. Also, the acceptance issues within SMEs (staff and management) generally and SMEs customers (for example whether 
customers will still prefer to deal with the SMEs now that their data is stored in the cloud) are issues that have been missed in the application of theory to adoption issues.

\subsection{Gaps in Methodological Approach}

The absence of the use of mixed method approaches was the most ostensible gap in the methodologies. This was followed by the fewer qualitative studies. Quantitative studies were highest. The qualitative studies generally employed case study method and whilst some studies provided depth in its use and analysis of primary data (Lai et al., 2012; Wang \& He, 2014) others lacked it (Makena, 2013). The extensive use of in-depth qualitative case study approaches as well as the use of other qualitative approaches is therefore lacking.

Whilst the review supports the fact that many studies on cloud adoption have concentrated on adoption factors other than processes (El-Gazzar, 2014), a gap lies in the investigation of cloud adoption processes by SMEs in DCs. Studies that have used adoption factors (Abdollahzadehgan et al., 2013; Johansson \& Ruivo, 2013; Lian et al., 2014; Makena, 2013; Wu, Lan, \& Lee, 2011) have used some in-depth and descriptive case studies. The use of interpretive case studies (Walsham, 1995) to investigate the adoption process of SMEs in DCs in terms of implementation integration is important.

Most studies, however, displayed gaps in methodology raising questions of reliability and validity of the research. Three main issues stood out. The first relates to whether the results of surveys are representative enough of the wider population and the extent to which they addressed the potential for cloud computing adoption by SMEs. Other methodological issues encountered were cases where data is collected using differing methods (e.g., telephone interviews for users and face-to-face for non-users). The second is the issue of causality which related to the wider impact of cloud computing and how it can be attributed.

With regard to levels of assessment, the literature review showed some level of discussion of generating awareness at the macro-level, as well as from a meso-level perspective dealing with the development of applications and the role of CSPs and delivery mechanisms.

\subsection{Conclusions and Pointers for Future Research}

The review was systematically conducted on literature on SMEs in cloud computing in DCs. The review process involved the identification of current research contributions and the gaps in the literature. To do this, the review process involved the classification of literature by issues and evidence, conceptual approaches as well as methodological approaches found in the literature. It is after this that the paper suggests a future IS research agenda based on the discussion in the gap revealed above. The review was however limited to a review of only academic articles from specific databases.

This review indicates a rapid expansion of research into cloud computing in SMEs in DCs and there is no up to date review of how this research has progressed both conceptually and methodologically. This review is anticipated to fill that gap. It is hoped that the studies reported here are representative of the cloud computing research on SMEs in DCs, and the interpretation of those studies by this review portrays the accuracy of the research conducted.

The research area is largely unbalanced in terms of the use of methodological approaches. There is more use of quantitative approaches than qualitative approaches. The lack of qualitative orientation is worsened by the lack of in-depth case studies that can form the basis for theorising. With a few notable exceptions, the research reviewed was more of a descriptive nature and many lack depth of evidence and analysis. Overall, there is lack of geographical diversity, with the state of current knowledge based upon a relatively narrow evidence base. There is also lack of published research being conducted by developing country institutions and researchers. In the small number of impact studies carried out, the research has not been linked - conceptually or methodologically - with mainstream knowledge and research concerning impact assessment of cloud computing in SMEs in DCs. In terms of the methodologies the use of more detailed qualitative case studies with more effective use of mixed research methods and sources of data is lacking.

In terms of pointers for future research, the following should be considered:

The migration process of SMEs to the cloud and how this impacts existing process and the sustainability of the business is missing in the literature. The whole migration process and how SMEs deal with the changes should be investigated. Also, the cloud computing adoption processes by SMEs is not very well documented and more attention can be directed at this area to explore the challenges faced in each stage of the process (El-Gazzar, 2014) and how SMEs cope with these challenges for risk-free adoption of cloud technology and services.

Also, the lack of studies on policy issues on cloud service evaluation, legal issues and clarity on security issues 
for SMEs should be further looked at.

The CSP-CSC behaviour and relationships are not much researched. This is supported by the fact that the relationship between Application Service Providers (ASPs) or CSPs and CSCs relationships are completely different from traditional outsourcing relationships between a supplier and a vendor, an area that has been largely glossed over by cloud computing research since its inception.

The cloud computing acceptance issues within SMEs (staff and management) generally and with SMEs customers (for example whether customers will still prefer to deal with the SMEs now that their data is stored in the cloud) are issues that have been missed in the application of theory to adoption issues.

The use of interpretive case studies to investigate the adoption process of SMEs in DCs in terms of implementation and the integration of the cloud with traditional business environment is important and need to be researched further.

Further, it would be useful to investigate internal readiness and selection of cloud provider issues in the context of SMEs. Future studies should research the compatibility between cloud solutions with enterprises' legacy systems and business needs, as well as the impact of trying or using cloud solutions on organizational culture, staff skills, and work practices.

\section{Acknowledgements}

The authors thank Dr. Richard Boateng, University of Ghana Business School for his immense guidance and direction in the whole review process that resulted in this publication.

\section{References}

Abdollahzadehgan, A., Gohary, M. M., \& Amini, M. (2013). The Organizational Critical Success Factors for Adopting Cloud Computing in SMEs. Journal of Information Systems Research and Innovation (JISRI), 4(1), 67-74.

Alena, B., \& Libor, G. (2012). Green ICT Adoption Survey Focused on ICT Life-cycle from the Consumer's Perspective (SMEs). Journal of Competitiveness, 4(4), 109-122.

Alshamaila, Y., Papagiannidis, S., \& Li, F. (2013). Cloud computing adoption by SMEs in the north east of England: A multi-perspective framework. Journal of Enterprise Information Management, 26(3), 250-275.

Ayyagari, M., Beck, T., \& Demirguc-Kunt, A. (2007). Small and medium enterprises across the globe. Small Business Economics, 29(4), 415-434.

Azarnik, A., Shayan, J., Alizadeh, M., \& Karamizadeh, S. (2012). Associated Risks of Cloud Computing for SMEs. Open International Journal of Informatics, 1, 37-45.

Begg, C. E., \& Caira, T. (2010). Data Governance in Practise: The SME Quandary Reflections on the reality of Data Governance in the Small to Medium Enterprise (SME) sector. Paper presented at the Proceedings of the 5th European Conference on Information Management and Evaluation, Università Dell'Insubria, Como, Italy, 8-9 September 2011.

Behrend, T. S., Wiebe, E. N., London, J. E., \& Johnson, E. C. (2011). Cloud computing adoption and usage in community colleges. Behaviour \& Information Technology, 30(2), 231-240.

Bhagwati, J. (1998). A Stream of Windows. A Stream of Windows.

Bhanti, P., Lehri, S., \& Kumar, N. (2011). Cloud Computing: A New Paradigm for Data Storage in Indian Universities. Indian Journal of Computer Science and Engineering (IJCSE).

Boateng, R., Molla, A., \& Heeks, R. (2009). E-Commerce in Developing Economies: A Review of Theoretical Frameworks. Emerging Markets and E-Commerce in Developing Countries. IGI Global.

Budniks, L., \& Didenko, K. (2014). Cloud Service Providers' competitiveness-The Case of Latvia. Economics \& Management, 19(1).

Bunce, B. (2013). Can Cloud Computing benefit SME's? IS Practices for SME Success Series, 5.

Buyya, R., Yeo, C. S., Venugopal, S., Broberg, J., \& Brandic, I. (2009). Cloud computing and emerging IT platforms: Vision, hype, and reality for delivering computing as the 5th utility. Future Generation Computer Systems, 25(6), 599-616. http://dx.doi.org/10.1016/j.future.2008.12.001

Chang, V., Bacigalupo, D., Wills, G., \& De Roure, D. (2010). A categorisation of cloud computing business models. 
Cheng-Chung Chu, W., Chao-Tung, Y., Chih-Wei, L., Chih-Hung, C., Juei-Nan, C., Pao-Ann, H., \& Hahn-Ming, L. (2012). Cloud computing in Taiwan. Computer, 45(6), 48-56. http://dx.doi.org/10.1109/MC.2012.188

Christauskas, C., \& Miseviciene, R. (2012). Cloud-Computing Based Accounting for Small to Medium Sized Business. Engineering Economics, 23(1), 14-21.

Dahiru, A. A., Bass, J., \& Allison, I. (2014). Cloud Computing: Adoption Issues for Sub-Saharan Africa SMEs. The Electronic Journal of Information Systems in Developing Countries.

Duncombe, R., \& Boateng, R. (2009). Mobile Phones and Financial Services in Developing Countries: a review of concepts, methods, issues, evidence and future research directions. Third World Quarterly, 30(7), $1237-1258$.

El-Gazzar, R. F. (2014). A Literature Review on Cloud Computing Adoption Issues in Enterprises. Creating Value for All Through IT (pp. 214-242). Springer.

Erdogmus, H. (2009). Cloud Computing: Does Nirvana Hide behind the Nebula? Software, IEEE, 26(2), 4-6. http://dx.doi.org/10.1109/MS.2009.31

Giessmann, A., \& Stanoevska-Slabeva, K. (2013). Business Models of Platform as a Service (PaaS) Providers: Current State and Future Directions. Journal of Information Technology Theory and Application (JITTA), 13(4).

Goundar, S. (2010). Cloud computing: Opportunities and issues for developing countries. DiploFoundation: Internet governance research paper.

Gupta, P., Seetharaman, A., \& Raj, J. R. (2013). The usage and adoption of cloud computing by small and medium businesses. International Journal of Information Management, 33(5), 861-874. http://dx.doi.org/10.1016/j.ijinfomgt.2013.07.001

Hadidi, R. (2011). What Managers of Small and Medium Enterprises (SMEs) Need to Know about Cloud Computing and Services. European Journal of Management, 11(4).

Heeks, R. (2006). Theorising ICT4D Research. Information Technologies \& International Development, 3(3), $1-4$.

Heeks, R., \& Bailur, S. (2007). Analyzing e-government research: Perspectives, philosophies, theories, methods, and practice. Government information quarterly, 24(2), 243-265.

Helvacioglu-Kuyucu, A. D. (2011). Exploring Policy-Formulation for SMEs in Cloud Computing: The Case of Turkey. IBIMA Business Review.

Hinde, C., \& van Belle, J. (2012). Cloud Computing in South African SMMEs: Risks and Rewards for Playing at Altitude. International Journal of Computer Science and Electrical Engineering, 1(1), 1-10.

Hinde, C., \& Van Belle, J.-P. (2012). Cloud Computing in South African SMMEs. International Journal of Computer Science and Electrical Engineering, 1(1).

Hon, W. K., Millard, C., \& Walden, I. (2013). Negotiating Cloud Contracts: Looking at Clouds from Both Sides Now. Stanford Technology Law Review.

Huang, B., Li, C., Yin, C., \& Zhao, X. (2013). Cloud manufacturing service platform for small- and medium-sized enterprises. International Journal of Advanced Manufacturing Technology, 65(9-12), 1261-1272. http://dx.doi.org/10.1007/s00170-012-4255-4

Iye, E. K., Krishnan, A., Sareen, G., \& Panda, T. (2013). Sectorial Adoption Analysis of Cloud Computing by Examining the Dissatisfier Landscape. Electronic Journal of Information Systems Evaluation, 16(3), 211-219.

Iyer, B., \& Henderson, J. C. (2010). Preparing for the Future: Understanding the Seven Capabilities Cloud Computing. MIS Quarterly Executive, 9(2).

Jianzhen, Z. (2011). The Value of Cloud Computing in Small and Medium Enterprises. Computer Study, 2, 14.

Johansson, B., \& Ruivo, P. (2013). Exploring Factors for Adopting ERP as SaaS. Procedia Technology, 9(0), 94-99. http://dx.doi.org/10.1016/j.protcy.2013.12.010

Katz, R. H. (2009). Tech Titans Building Boom. Spectrum, IEEE, 46(2), 40-54. http://dx.doi.org/10.1109/MSPEC.2009.4768855

Kim, W., Kim, S. D., Lee, E., \& Lee, S. (2009). Adoption issues for cloud computing. Paper presented at the 
Proceedings of the 7th International Conference on Advances in Mobile Computing and Multimedia.

Kshetri, N. (2010). Cloud Computing in Developing Economies. Computer, 43(10), 47-55. http://dx.doi.org/10.1109/MC.2010.212

Kshetri, N. (2010). Cloud Computing in Developing Economies: Drivers, Effects, and Policy Measures. Paper presented at the Proceedings of PTC

Kshetri, N. (2011). Cloud Computing in the Global South: drivers, effects and policy measures. Third World Quarterly, 32(6), 997-1014. http://dx.doi.org/10.1080/01436597.2011.586225

Kshetri, N. (2012). Cloud Computing in India. IT Professional, 14(5), 5-8. http://dx.doi.org/10.1109/MITP.2012.94

Kshetri, N. (2013). Cloud Computing in Sub-Saharan Africa. IT Professional, 15(6), 64-67. http://dx.doi.org/10.1109/MITP.2013.92

Lai, I. K. W., Tam, S. K. T., \& Chan, M. F. S. (2012). Knowledge cloud system for network collaboration: A case study in medical service industry in China. Expert Systems with Applications, 39(15), 12205-12212. http://dx.doi.org/10.1016/j.eswa.2012.04.057

Lawton, G. (2008). Developing software online with platform-as-a-service technology. Computer, 41(6), 13-15.

Le Roux, C., \& Evans, N. (2011). Can cloud computing bridge the digital divide in South African secondary education? Information Development, 27(2), 109-116.

Lee, M. R., \& Yen, D. C. (2012). Taiwan's Journey to the Cloud: Progress and Challenges. IT Professional, 14(6), 54-58. http://dx.doi.org/10.1109/MITP.2012.114

Lee, S.-G., Chae, S. H., \& Cho, K. M. (2013). Drivers and inhibitors of SaaS adoption in Korea. International Journal of Information Management, 33(3), 429-440. http://dx.doi.org/10.1016/j.ijinfomgt.2013.01.006

Levy, Y., \& Ellis, T. J. (2006). A Systems Approach to Conduct an Effective Literature Review in Support of Information Systems Research. Informing Science, 9.

Li, Z., Zhang, H., O’Brien, L., Cai, R., \& Flint, S. (2013). On evaluating commercial Cloud services: A systematic review. Journal of Systems and Software, 86(9), 2371-2393. http://dx.doi.org/10.1016/j.jss.2013.04.021

Lian, J.-W., Yen, D. C., \& Wang, Y.-T. (2014). An exploratory study to understand the critical factors affecting the decision to adopt cloud computing in Taiwan hospital. International Journal of Information Management, 34(1), 28-36. http://dx.doi.org/10.1016/j.ijinfomgt.2013.09.004

Lin, A., \& Chen, N.-C. (2012). Cloud computing as an innovation: Percepetion, attitude, and adoption. International Journal of Information Management, 32(6), 533-540. http://dx.doi.org/10.1016/j.ijinfomgt.2012.04.001

Low, C., Chen, Y., \& Wu, M. (2011). Understanding the determinants of cloud computing adoption. Industrial management \& data systems, 111(7), 1006-1023.

Mahara, T. N. (2013). Indian SMEs Perspective for election of ERP in Cloud. Journal of International Technology \& Information Management, 22(1).

Mahesh, S., Landry, B. J., Sridhar, T., \& Walsh, K. R. (2011). A decision table for the cloud computing decision in small business. Information Resources Management Journal (IRMJ), 24(3), 9-25.

Makena, J. N. (2013). Factors That Affect Cloud Computing Adoption By Small And Medium Enterprises In Kenya. International Journal of Computer Applications Technology and Research, 2(5), 517.

Marinos, A., \& Briscoe, G. (2009). Community cloud computing Cloud Computing (pp. 472-484). Springer.

Marston, S., Li, Z., Bandyopadhyay, S., Zhang, J., \& Ghalsasi, A. (2011). Cloud computing - The business perspective. Decision Support Systems, 51(1), 176-189. http://dx.doi.org/10.1016/j.dss.2010.12.006

Mather, T., Kumaraswamy, S., \& Latif, S. (2009). Cloud security and privacy: an enterprise perspective on risks and compliance: " O'Reilly Media, Inc.".

Mell, P., \& Grance, T. (2009). The NIST definition of cloud computing. National Institute of Standards and Technology, 53(6), 50.

Mell, P., \& Grance, T. (2011). The NIST definition of cloud computing (draft). NIST special publication, $800(145), 7$. 
Mujinga, M. (2012). Developing Economies and Cloud Security: A Study of Africa. Journal of Emerging Trends in Computing and Information Sciences, 3(8).

Mujinga, M., \& Chipangura, B. (2011a). Cloud computing concerns in developing economies. Conference.

Mujinga, M., \& Chipangura, B. (2011b). Cloud computing concerns in developing economies.

Murugesan, S. (2011). Cloud Computing Gives Emerging Markets a Lift. IT Professional, 13(6), 60-62. http://dx.doi.org/10.1109/MITP.2011.94

Mvelase, P., Dlodlo, N., Williams, Q., \& Adigun, M. O. (2011). Custom-Made Cloud Enterprise Architecture for Small Medium and Micro Enterprises. International Journal of Cloud Applications and Computing (IJCAC), 1(3), 52-63.

Parkhill, D. F. (1966). Challenge of the computer utility.

Peterson, B. (2012). SaaS: a powerful HR solution for SMBs. Strategic HR Review, 12(1).

Petter, S., \& McLean, E. R. (2009). A meta-analytic assessment of the DeLone and McLean IS success model: An examination of IS success at the individual level. Information \& Management, 46(3), 159-166.

Ramayah, T., Siew, K. K., Ahmad, N. H., \& Halim, H. A. (2013). An Exploratory Study of Green IT Adoption Issues among SMEs. Life Science Journal, 10(12s). (75)

Rawal, A. (2011). Adoption of Cloud Computing in India. Journal of Technology Management for Growing Economies, 2(2).

Saaty, T. L. (2004). Decision making - the analytic hierarchy and network processes (AHP/ANP). Journal of systems science and systems engineering, 13(1), 1-35.

Sabherwal, R., Jeyaraj, A., \& Chowa, C. (2006). Information system success: individual and organizational determinants. Management science, 52(12), 1849-1864.

Schaffer, H. E. (2009). X as a Service, Cloud Computing, and the Need for Good Judgment. IT Professional, 11(5), 4-5. http://dx.doi.org/10.1109/MITP.2009.112

Sebesta, M. (2010). Towards a framework for effective outsourcing practice within the new application service provisioning trends.

Seth, A., Agarwal, H., \& Singla, A. (2012). Integrating SOA and Cloud Computing for SME Business Objective. WSEAS Transactions on Computers, USA(3).

Siamak, F. (2010). Cloud Computing or Software as a Service-Which Makes the Most Sense for HR? Employment Relations Today, 36(4), 31-37.

Song, M., Shia, B.-C., Yao, H., Wang, W., \& Fang, K. (2012). Small and Medium Enterprises Risky Prediction System Based On Cloud Computing. Journal of Software (1796217X), 7(10).

Sultan, N. (2010). Cloud computing for education: A new dawn? International Journal of Information Management, 30(2), 109-116. http://dx.doi.org/10.1016/j.ijinfomgt.2009.09.004

Sultan, N. (2013). Cloud computing: A democratizing force? International Journal of Information Management, 33(5), 810-815. http://dx.doi.org/10.1016/j.ijinfomgt.2013.05.010

Sultan, N. (2014). Making use of cloud computing for healthcare provision: Opportunities and challenges. $\begin{array}{lllll}\text { International Journal of Information } & \text { Management, } & 34(2), & \text { 177-184. }\end{array}$ http://dx.doi.org/10.1016/j.ijinfomgt.2013.12.011

Sultan, N. A. (2011). Reaching for the "cloud": How SMEs can manage. International Journal of Information Management, 31(3), 272-278. http://dx.doi.org/10.1016/j.ijinfomgt.2010.08.001

Tornatzky, L. G., Fleischer, M., \& Chakrabarti, A. K. (1990). Processes of technological innovation.

Truong, D. (2009). How cloud computing enhances competitive advantages: A research model for small businesses. The Business Review, Cambridge, 15(1), 59-65.

Van Schendelen, R. (2003). Brussels: The premier league of lobbying Die stille Macht (pp. 300-319). Springer.

Vaquero, L. M., Rodero-Merino, L., \& Buyya, R. (2011). Dynamically scaling applications in the cloud. ACM SIGCOMM Computer Communication Review, 41(1), 45-52.

Vaquero, L. M., Rodero-Merino, L., Caceres, J., \& Lindner, M. (2008). A break in the clouds: towards a cloud definition. ACM SIGCOMM Computer Communication Review, 39(1), 50-55. 
Venkatesh, V., Morris, M. G., Davis, G. B., \& Davis, F. D. (2003). User acceptance of information technology: Toward a unified view. MIS quarterly, 425-478.

Venters, W., \& Whitley, E. A. (2012). A critical review of cloud computing: researching desires and realities. Journal of Information Technology, 27(3), 179-197.

Vom Brocke, J., Simons, A., Niehaves, B., Riemer, K., Plattfaut, R., \& Cleven, A. (2009). Reconstructing the giant: On the importance of rigour in documenting the literature search process. Paper presented at the ECIS.

Vouk, M. (2008). Cloud computing-issues, research and implementations. CIT. Journal of Computing and Information Technology, 16(4), 235-246.

Walsham, G. (1995). The emergence of interpretivism in IS research. Information systems research, 6(4), 376-394.

Walsham, G., \& Sahay, S. (2006). Research on information systems in developing countries: Current landscape and future prospects. Information Technology for Development, 12(1), 7-24.

Wang, F.-K., \& He, W. (2014). Service strategies of small cloud service providers: A case study of a small cloud service provider and its clients in Taiwan. International Journal of Information Management. http://dx.doi.org/10.1016/j.ijinfomgt.2014.01.007

Wang, G., \& Unger, J. (2013). A Strategy to Move Taiwan's IT Industry From Commodity Hardware Manufacturing to Competitive Cloud Solutions. environments, 1, 2169-3536.

Wang, H. (2013). Information Services Paradigm for Small and Medium Enterprises Based on Cloud Computing. Journal of Computers, 8(5).

Webster, J., \& Watson, R. T. (2002). Analyzing the past to prepare. Mis Quarterly, 26(2), 13-23.

Weinhardt, C., Anandasivam, A., Blau, B., \& Stosser, J. (2009). Business Models in the Service World. IT Professional, 11(2), 28-33. http://dx.doi.org/10.1109/MITP.2009.21

Werfs, M., Baxter, G., Allison, I. K., \& Sommerville, I. (2013). Migrating Software Products to the Cloud: An Adaptive STS Perspective. Journal of International Technology \& Information Management, 22(3).

Wolfswinkel, J. F., Furtmueller, E., \& Wilderom, C. P. (2013). Using grounded theory as a method for rigorously reviewing literature. European Journal of Information Systems, 22(1), 45-55.

Wu, W.-W., Lan, L. W., \& Lee, Y.-T. (2011). Exploring decisive factors affecting an organization's SaaS adoption: A case study. International Journal of Information Management, 31(6), 556-563. http://dx.doi.org/10.1016/j.ijinfomgt.2011.02.007

Xu, S., Zhu, K., \& Gibbs, J. (2004). Global Technology, Local Adoption: A Cross-Country Investigation of Internet Adoption by Companies in the United States and China. Electronic Markets, 14(1), 13-24.

Yang, H., \& Tate, M. (2012). A Descriptive Literature Review and Classification of Cloud Computing Research. Communications of the Association for Information Systems, 31.

Yeboah-Boateng, E. O., \& Cudjoe-Seshie, S. (2013). Cloud Computing: The Emergence of Application Service Providers (ASPs) in Developing Economies. International Journal of Emerging Technology and Advanced Engineering, 3(5), 703-712.

Yeboah-Boateng, E. O., \& Essandoh, K. A. (2013). Cloud Computing: The Level of Awareness Amongst Small \& Medium-sized Enterprises (SMEs) in Developing Economies. Journal of Emerging Trends in Computing \& Information Sciences, 4(11), 832-839.

Zhang, Q., Cheng, L., \& Boutaba, R. (2010). Cloud computing: state-of-the-art and research challenges. Journal of internet services and applications, 1(1), 7-18.

\section{Copyrights}

Copyright for this article is retained by the author(s), with first publication rights granted to the journal.

This is an open-access article distributed under the terms and conditions of the Creative Commons Attribution license (http://creativecommons.org/licenses/by/3.0/). 